\title{
A simplified approach for calculating temperatures in axially loaded cold-formed thin-walled steel studs in wall panel assemblies exposed to fire from one side
}

\author{
Ashkan Shahbazian, Yong Chang Wang* \\ School of Mechanical, Aerospace and Civil Engineering, the University of Manchester, Pariser Building, Sackville Street, Manchester M13 9PL, United Kingdom
}

\section{A R T I C L E I N F O}

\section{Article history:}

Received 21 June 2012

Received in revised form

14 November 2012

Accepted 11 December 2012

\section{Keywords:}

Steel

Cold-formed

Thin-walled stud

Heat transfer

Thermal resistance

Fire resistance

Wall panel assemblies

Temperature calculation

\begin{abstract}
A B S T R A C T
Cold-formed thin-walled steel sections are usually used as the load-bearing elements of wall panels in building construction. Such panels consist of channel steel sections with gypsum plasterboard layers attached to the flanges on the outside and interior insulation. This paper proposes a simple method to calculate temperature distributions in the steel section when the panel is exposed to fire from one side. This method calculates the average temperatures in the flanges of the steel section and assumes that the temperature in the web is linear. The proposed method is based on simple heat balance analysis for a few nodes representing the key components of the panel. The thermal resistance of these nodes is obtained from the weighted average of thermal resistances in an effective width of the panel within which heat transfer in the panel width direction is assumed to occur. The effective width of the panel for calculating the weighted average of thermal resistances can be taken as the steel section flange width plus $15 \%$ of the difference between $300 \mathrm{~mm}$ and the flange width of the steel section. Validity of the proposed method has been checked by comparison of the temperature results between the proposed 1-D modelling and 2-D ABAQUS Finite Element modelling for an extensive set of parametric and sensitivity studies covering different steel section dimensions (width, depth, thickness and lips), different spacing between steel section, number of gypsum layers (1 or 2) and different interior insulation properties. Further assessment of accuracy of the proposed temperature calculation method has been provided by comparing compressive resistance of the steel studs between using temperature profiles produced by 2-D ABAQUS Finite Element simulation and by using the proposed simplified method. Although the simplified method still requires a numerical procedure, it is extremely easy to implement to give designers of this structural system a much more efficient tool than using Finite Element simulations to calculate its fire resistance.
\end{abstract}

(c) 2012 Elsevier Ltd. All rights reserved.

\section{Introduction}

Cold-formed thin-walled steel (CF-TW) sections are commonly used as the load-bearing structural component in a variety of building constructions. In wall panel construction, layers of gypsum plasterboards are attached to the flanges of the CF-TW channel sections and the spaces between the gypsum plasterboards are filled with lightweight interior insulation. In building construction, it is necessary for such wall panels to possess sufficient load-bearing resistance to prevent fire spread and collapsing. When designing for fire resistance, panels are assumed to be attacked by fire from one side. Fig. 1 shows a sketch.

\footnotetext{
* Corresponding author. Tel.: +441613068968.

E-mail addresses: yong.wang@umist.ac.uk, yong.wang@manchester.ac.uk (Y.C. Wang).
}

When evaluating the load-bearing resistance of this system under fire attack, the temperature distribution of the steel section is calculated followed by assessment of the load-carrying capacity of the steel structure at elevated temperatures. Whilst Finite Element simulation methods for both heat transfer and structural analysis are now sufficiently mature and accessible, it is still desirable to use much more simplified method in routine fire resistance design. Recently, the authors have proposed a new approach [1-3] for calculating the ultimate strength of coldformed thin-walled steel sections with non-uniform temperature distributions in the steel cross-section for global, local and distortional buckling. This paper addresses the issue of calculating temperatures in the steel cross-section when the panel is exposed to fire attack from one side.

Neglecting heat transfer in the longitudinal direction of the panel, heat transfer is 2-dimensional, in both the thickness and width directions. However, the results of numerical simulations by Feng et al. [4] and sensitivity study by the authors [1] for such systems 


\title{
A Simplified Approach for Calculating Temperatures in Axially Loaded Cold-Formed Thin-Walled
}

\section{Steel Studs in Wall Panel Assemblies Exposed to Fire from One Side}

\section{Ashkan Shahbazian, Yong Chang Wang*}

School of Mechanical, Aerospace and Civil Engineering, the University of Manchester, United Kingdom

*corresponding author

Email:yong.wang@manchester.ac.uk

Address: School of Mechanical, Aerospace and Civil Engineering, the University of Manchester, Pariser Building, Sackville Street, Manchester M13 9PL, United Kingdom

Tel: 00441613068968

\begin{abstract}
Cold-formed thin-walled steel sections are usually used as the load-bearing elements of wall panels in building construction. Such panels consist of channel steel sections with gypsum plasterboard layers attached to the flanges on the outside and interior insulation. This paper proposes a simple method to calculate temperature distributions in the steel section when the panel is exposed to fire from one side. This method calculates the average temperatures in the flanges of the steel section and assumes that the temperature in the web is linear. The proposed method is based on simple heat balance analysis for a few nodes representing the key components of the panel. The thermal resistance of these nodes are obtained from the weighted average of thermal resistances in an effective width of the panel within which heat transfer in the panel width direction is assumed to occur. The effective width of the panel for calculating the weighted average of thermal resistances can be taken as the steel section flange width plus $15 \%$ of the difference between $300 \mathrm{~mm}$ and the flange width of the steel section. Validity of the proposed method has been checked by comparison of the temperature results between the proposed 1-D modelling and 2-D ABAQUS Finite Element modelling for an extensive set of parametric and sensitivity studies covering different steel section dimensions (width, depth, thickness and lips), different spacing between steel section, number of gypsum layers ( 1 or 2 ) and different interior insulation properties. Further assessment of accuracy of the proposed temperature calculation method has been provided by comparing compressive resistance of the steel studs between using temperature profiles produced by 2-D ABAQUS Finite Element simulation and by using the proposed simplified method. Although the simplified method still requires a numerical procedure, it is extremely easy to implement to give designers of this structural system a much more efficient tool than using Finite Element simulations to calculate its fire resistance.
\end{abstract}

Keywords: Steel; Cold-Formed; Thin-Walled Stud; Heat Transfer; Thermal Resistance; Fire Resistance; Wall Panel Assemblies; Temperature Calculation 


\section{Introduction}

Cold-formed thin-walled steel (CF-TW) sections are commonly used as the load-bearing structural component in a variety of building constructions. In wall panel construction, layers of gypsum plasterboards are attached to the flanges of the CF-TW channel sections and the spaces between the gypsum plasterboards are filled with lightweight interior insulation. In building construction, it is necessary for such wall panels to possess sufficient load-bearing resistance to prevent fire spread and collapsing. When designing for fire resistance, panels are assumed to be attacked by fire from one side. Figure 1 shows a sketch.
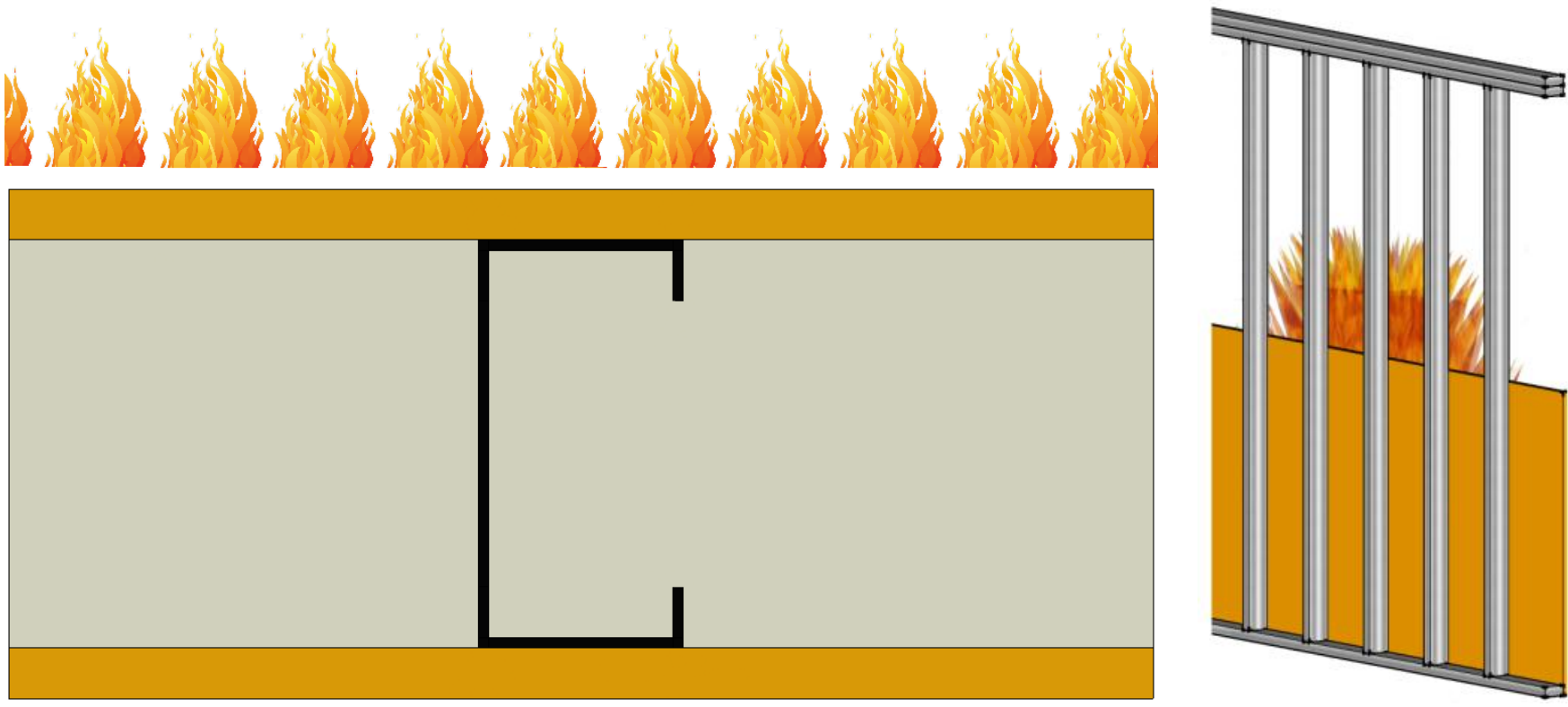

Figure 1. Wall panel exposed to fire

When evaluating the load-bearing resistance of this system under fire attack, the temperature distribution of the steel section is calculated followed by assessment of the load-carrying capacity of the steel structure at elevated temperatures. Whilst Finite Element simulation methods for both heat transfer and structural analysis are now sufficiently mature and accessible, it is still desirable to use much more simplified method in routine fire resistance design. Recently, the authors have proposed a new approach [1-3] for calculating the ultimate strength of cold-formed thin-walled steel sections with non-uniform temperature distributions in the steel cross-section for global, local and distortional buckling. This paper addresses the issue of calculating temperatures in the steel cross-section when the panel is exposed to fire attack from one side.

Neglecting heat transfer in the longitudinal direction of the panel, heat transfer is 2-dimensional, in both the thickness and width directions. However, the results of numerical simulations by Feng et al. [4] and sensitivity study by the authors [1] for such systems exposed to fire from one side suggest that for calculating compressive resistance of the steel stud, it is acceptable to assume the temperature distribution in the steel cross-section to be linear in the thickness direction using the average temperatures in the two flanges of the cross-section. Figure 2 shows the actual temperature distribution in the steel section and the acceptable simplified temperature distribution based on Feng et al. [4]. 


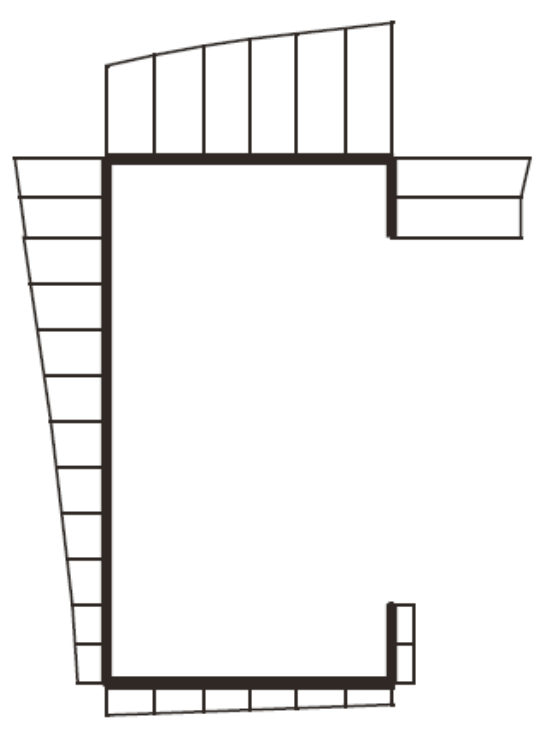

(a) Actual temperature distribution

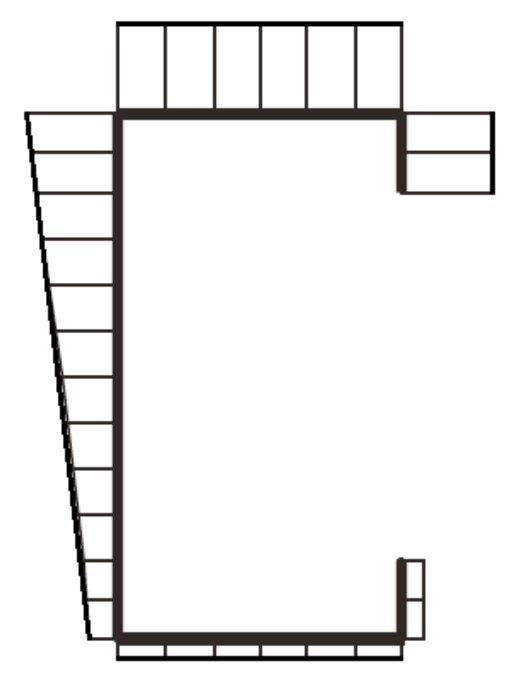

(b) Acceptable temperature distribution

Figure 2. (a) Actual temperature distribution and (b) Acceptable temperature distribution based on Feng et al. [4]

This allows considerable simplification to be made if heat transfer in the panel width direction is not dealt with explicitly. However, as will be demonstrated later (Figure 7), there is strong heat transfer in the panel width direction between the steel flanges and the adjacent materials and it is important to include this effect in the temperature calculation method for the steel section. One method of including this effect is to use the weighted average of thermal resistances in the wall panel width direction. This paper will propose a method of calculating the weighted average of thermal resistances. Since calculating the steel temperature is only an intermediate step towards quantifying the steel structure's load-bearing capacity, it is important that the accuracy of the temperature calculation method is based on assessment of predicting the structural loadbearing capacity. The accuracy of the proposed temperature calculation method will be assessed by comparing the simulation results using the general Finite Element software ABAQUS for both steel temperature and load-bearing capacity calculations. The authors have already established validity of the ABAQUS model for load-bearing capacity calculations [1-3]. This paper will present evidence of validating the ABAQUS model for heat transfer simulation. 


\section{Validation of ABAQUS modelling against experimental results for heat transfer}

This section presents validation study of using the general Finite Element package ABAQUS [5] for heat transfer analysis. The experimental results include the one dimensional heat transfer tests by Rahmanian and Wang [6] on single and double layers of gypsum board and furnace tests by Feng et al. [7] on wall panel assemblies. In both series of experiments, the panels were under fire attack from one side and other side was exposed to room temperature.

\subsection{Gypsum board validation}

Two tests of Rahmanian and Wang [6] were used for comparison in this section, using one layer and two layers of British Gypsum Fireline gypsum boards of 12.8 and $25.7 \mathrm{~mm}$ thickness respectively. The temperatures measured on the exposed surface were used as an input in ABAQUS modelling to eliminate uncertainty caused by unknown emissivity on the exposed surface. The emissivity of the unexposed side was taken as $0.8[6,8]$ and the convection heat transfer coefficient was $10 \mathrm{~W} / \mathrm{m}^{2} \mathrm{k}$ [9]. Figure 3 shows the thermal properties of the gypsum board as proposed by Rahmanian and Wang [6]. Figure 4 compares the present ABAQUS simulation results with the test and finite difference simulation results of Rahmanian and Wang [6] and the agreement is excellent.

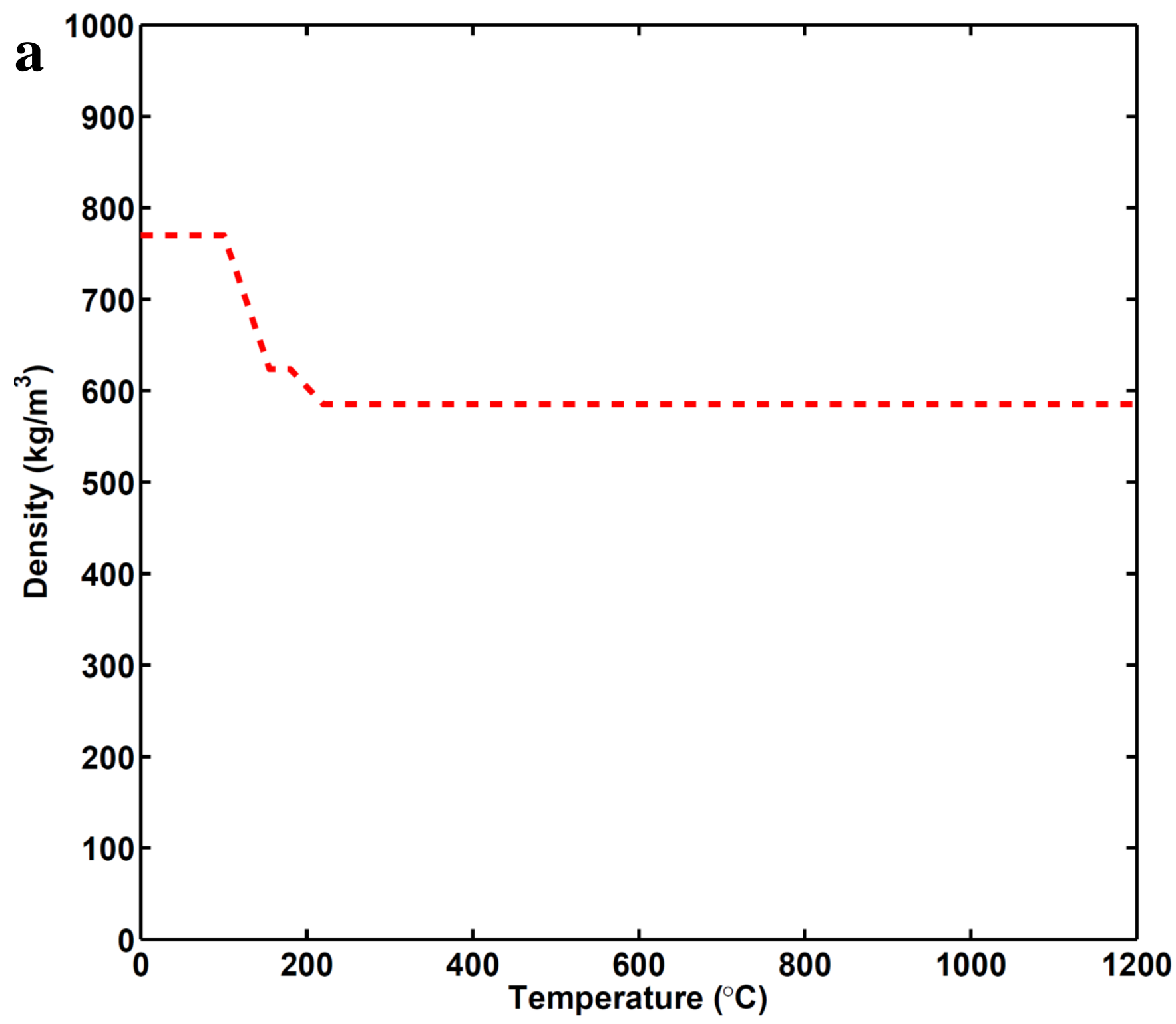




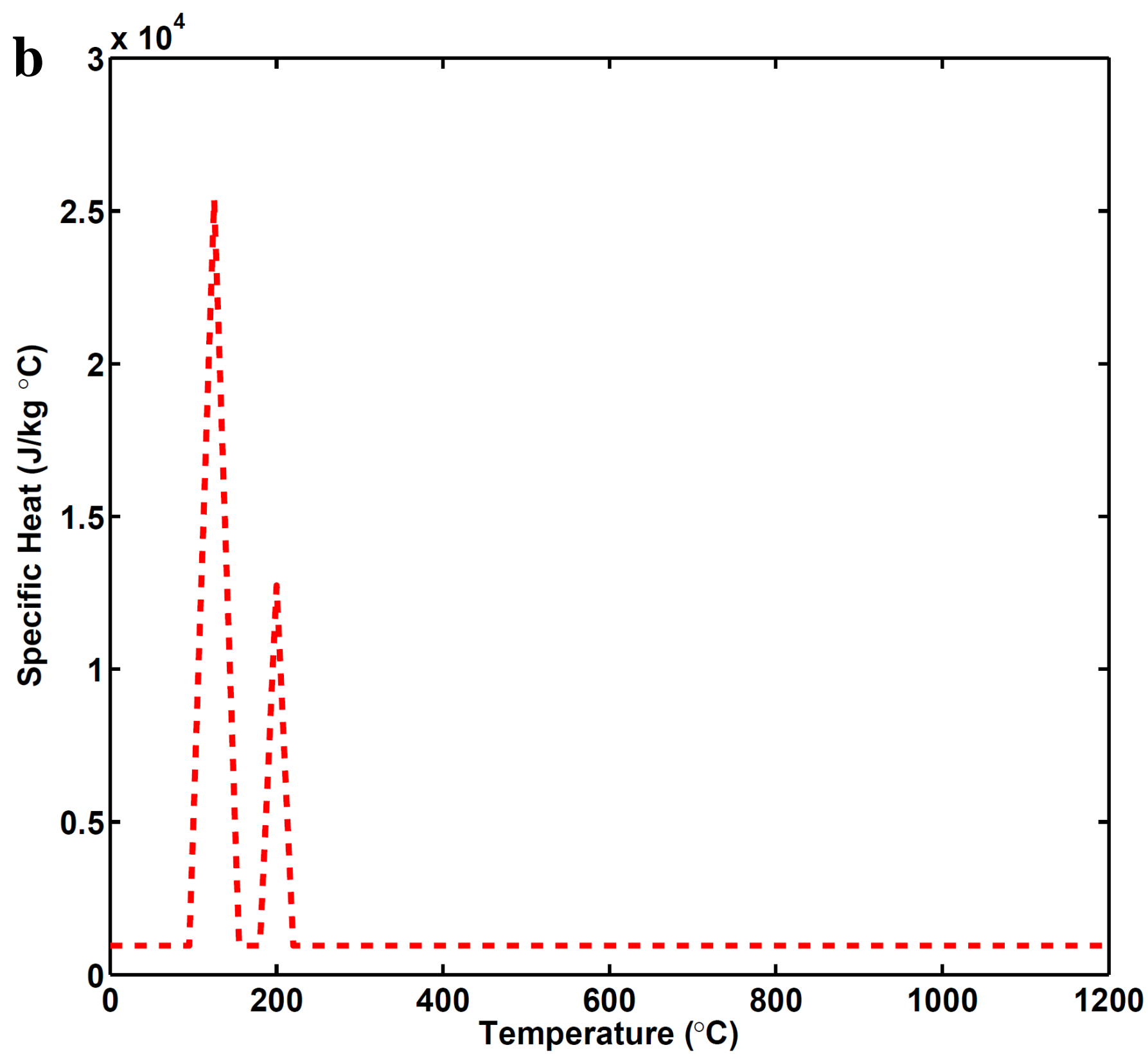




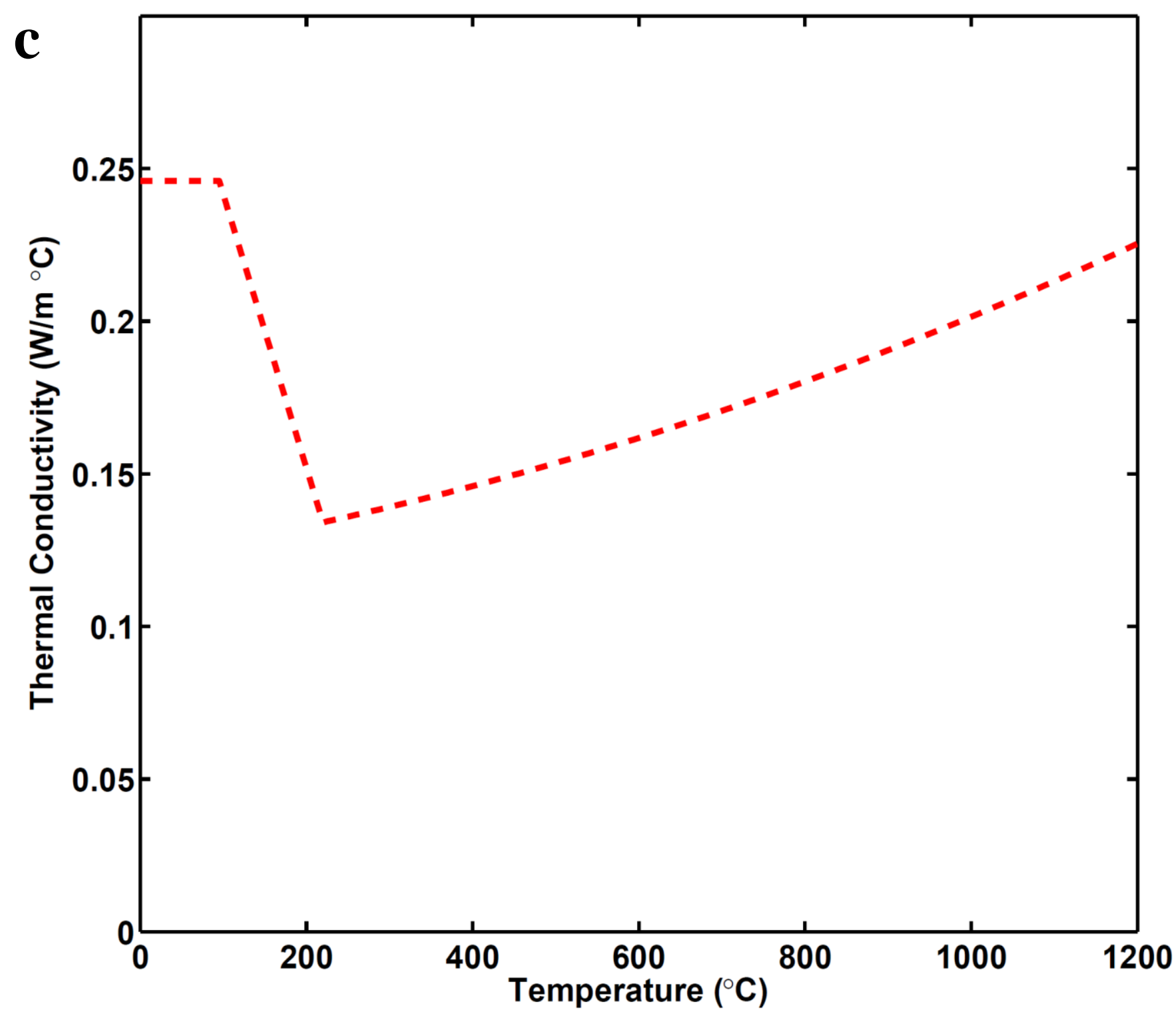

Figure 3. Thermal properties of British Gypsum Fireline board [6]: (a) density, (b) specific heat and (c) thermal conductivity 


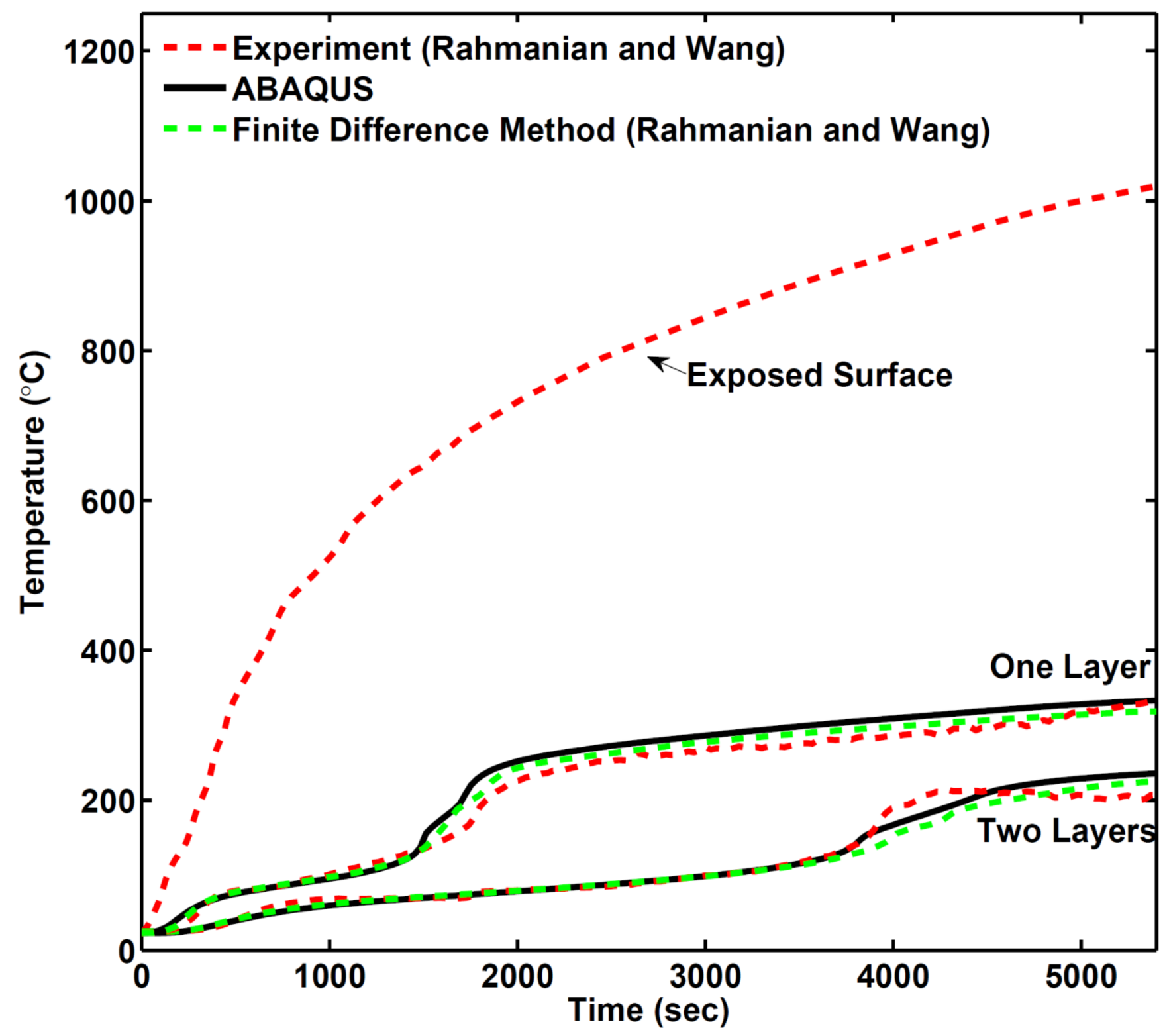

Figure 4. Comparison between present ABAQUS simulation results with experimental results and finite difference results for one and two layers of Fireline gypsum board [6] 


\subsection{Wall panel assemblies}

Feng et al. [7] carried out 8 fire tests for different arrangements of 300x300 mm panels with thin-walled steel channel sections. They also used ABAQUS for heat transfer analysis of these panels and validated their ABAQUS model. In the present study, only one of their tests was considered for repeat validation of ABAQUS simulation. In this test, lipped channel 100x54x15x1.2 was used. The panel had one layer of Fireline gypsum board $(12.5 \mathrm{~mm})$ on both sides and ISOWOOL as interior insulation. Figure 5 shows the Finite Element mesh using element type DC2D4 (4-node linear quadrilateral heat transfer element). The recorded exposed surface temperatures were again used as input data in the ABAQUS simulation model. The same thermal properties as in the previous section were used for the Fireline gypsum board. The thermal properties of the steel section were according to EN 1993-1-2 [10]. The density and specific heat of ISOWOOL1000 were $25\left(\mathrm{~kg} / \mathrm{m}^{3}\right)$ and $840\left(\mathrm{~J} / \mathrm{kg}^{\circ} \mathrm{C}\right)$, respectively and the thermal conductivity temperature relationship of ISOWOOL1000 is shown in Figure 6 as suggested by Salhab and Wang [11].

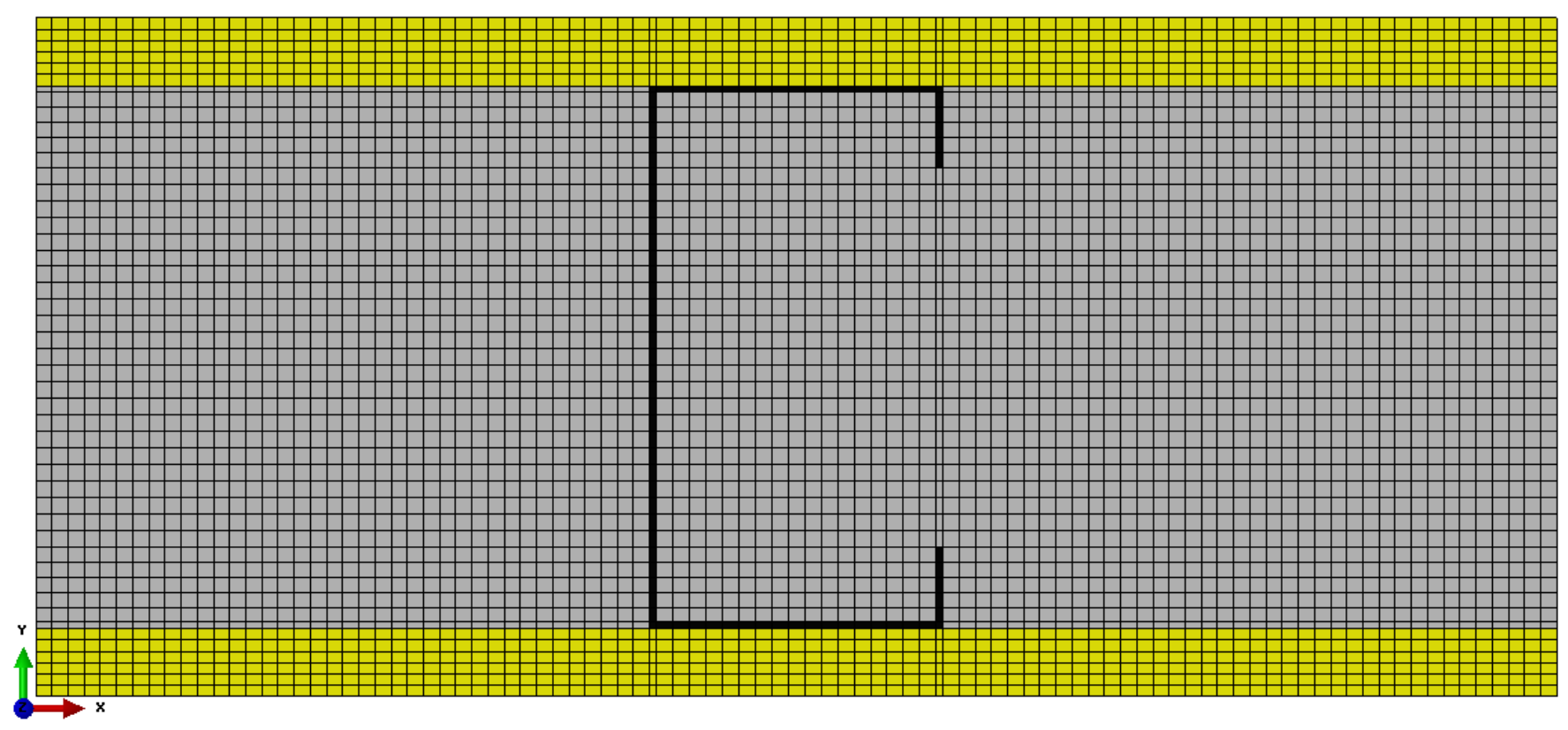

Figure 5. Finite element mesh for wall assembley in ABAQUS 


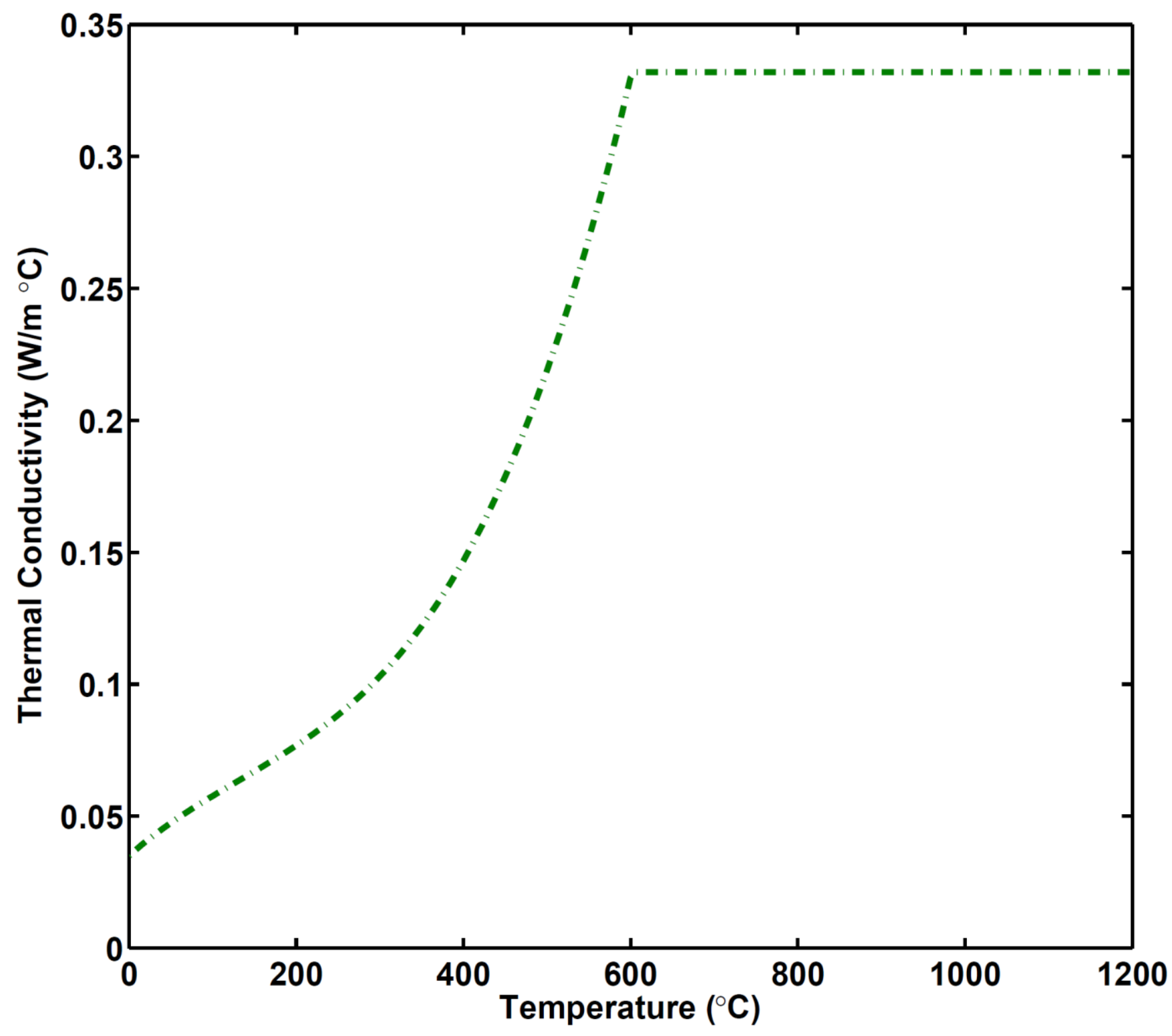

Figure 6. Thermal conductivity of ISOWOOL1000 [11]

Figure 7 shows temperature distribution in the panel at the end of the simulation (120 min) and Figure 8 compares the simulation results with the experimental results. The Finite Element simulation results clearly show differences in the width direction of the flanges of the channel: the lip-flange junction having higher temperature than the flange-web junction on the exposed side, the lip-flange junction having lower temperature than the flange-web junction on the unexposed side. These differences are caused by accelerated rate of heat transfer in the web of the channel.

The experimental results show similar trend, but the difference in temperatures along the same flange is less than the numerical simulation results. The same trend was observed by independent researchers conducted by Feng et al [7] and Salhab and Wang [11]. However, since this research is only interested in the average flange temperatures and these average flange temperatures are very close between the two sets of results, the accuracy of the simulation results is acceptable. The temperature distribution shown in Figure 7 suggests that heat transfer in the panel width direction exists, but this effect disappears at a short distance away from the steel section. 
Figure 7. Temperature distribution at $120 \mathrm{~min}$

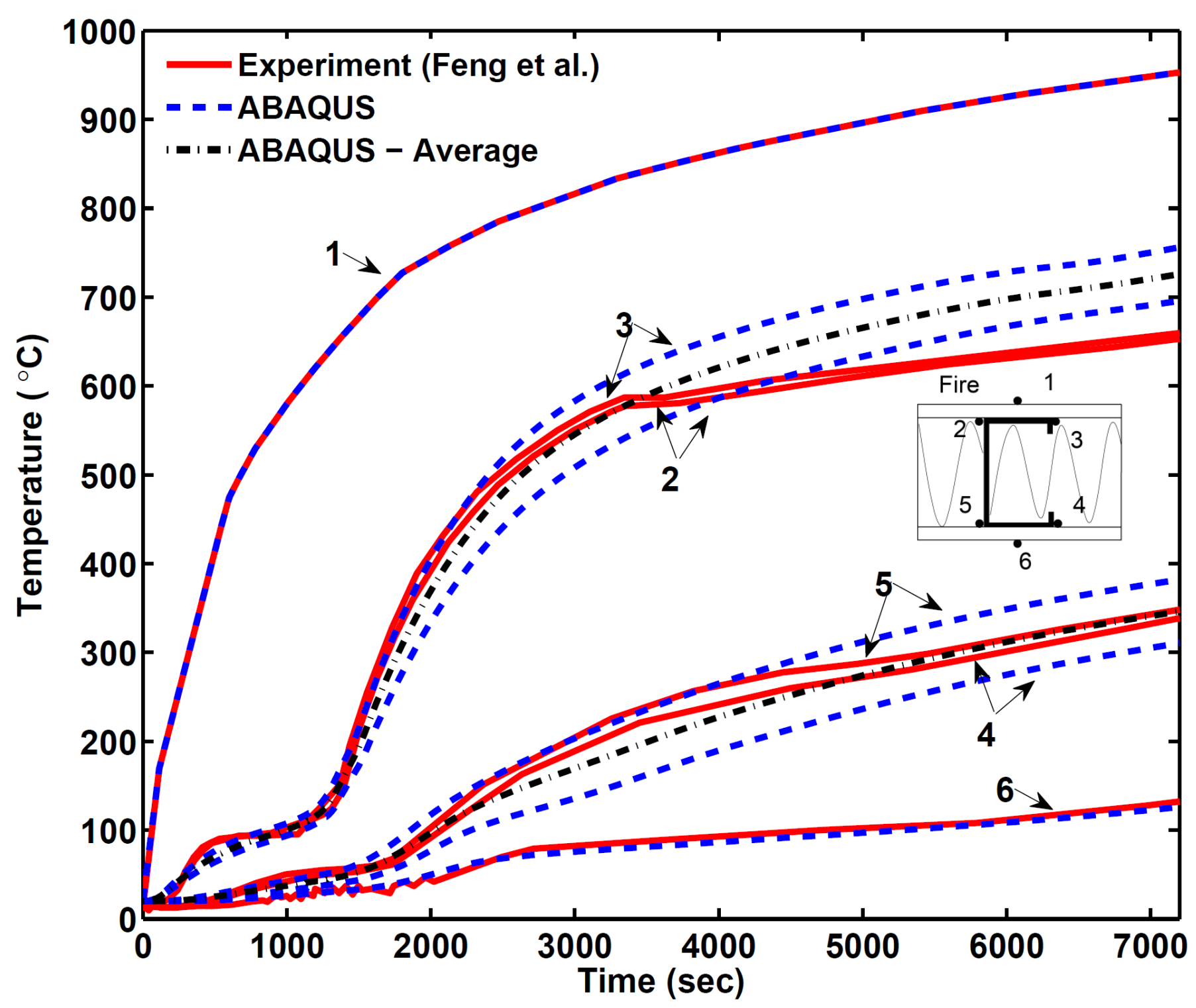

Figure 8. Comparison between FE simulation and experimental results [7] for a panel 


\section{Numerical sensitivity and parametric study}

In order to generate a database of temperature results to guide development of a simplified temperature calculation method for the average flange temperatures of the steel section, an extensive sensitivity and parametric study has been performed using the validated ABAQUS model. The thermal properties were the same as used in the previous sections. The panel was exposed to the standard fire curve (EN1991-1-2 [9]) from one side. The resultant emissivity on exposed side was taken as 0.3 and the convective heat transfer coefficient was $25 \mathrm{~W} / \mathrm{m}^{2} \mathrm{k}$ [12]. The thermal properties for ROCKFIBRE are according to Wang et al. [13] which is in Table 1.

Table 1. Thermal properties of ROCKFIBRE [13]

\begin{tabular}{ccc}
\hline $\begin{array}{c}\text { Density } \\
\left(\mathrm{kg} / \mathrm{m}^{3}\right)\end{array}$ & $\begin{array}{c}\text { Specific heat } \\
\left(\mathrm{J} / \mathrm{kg}^{\circ} \mathrm{C}\right)\end{array}$ & $\begin{array}{c}\text { Thermal Conductivity } \\
\left(\mathrm{W} / \mathrm{m}^{\circ} \mathrm{C}\right)\end{array}$ \\
\hline 155 & 900 & $0.022+0.1475\left(\frac{\mathrm{T}}{1000}\right)^{3}$
\end{tabular}

Numerical sensitivity study has been carried out to assess the influence of different design parameters on temperature distributions in the panel and to find out the width which should be used when calculating the weighted average of thermal resistances. Table 2 shows the configurations used for the sensitivity study, the design parameters include spacing between steel sections, steel section thickness, lip length, web depth, flange width, number of gypsum board layers and interior thermal insulation.

Table 2. Numerical sensitivity models

\begin{tabular}{|c|c|c|c|}
\hline & Steel stud dimension* & $\begin{array}{l}\text { Number of gypsum } \\
\text { board layers** }\end{array}$ & $\begin{array}{l}\text { Type of thermal } \\
\text { insulation }\end{array}$ \\
\hline \multirow{2}{*}{ effect of thickness } & $100 \times 50 \times 15 \times 0.8$ & one & ISOWOOL1000 \\
\hline & $100 \times 50 \times 15 \times 2.5$ & one & ISOWOOL1000 \\
\hline \multirow{2}{*}{ effect of lip } & $100 \times 50 \times 5 \times 1.4$ & one & ISOWOOL1000 \\
\hline & $100 \times 50 \times 20 \times 1.4$ & one & ISOWOOL 1000 \\
\hline \multirow{2}{*}{ effect of web } & $75 \times 50 \times 15 \times 1.4$ & one & ISOWOOL1000 \\
\hline & $300 \times 50 \times 15 \times 1.4$ & one & ISOWOOL1000 \\
\hline \multirow{2}{*}{ effect of gypsum } & $100 \times 50 \times 15 \times 1.4$ & one & ISOWOOL1000 \\
\hline & $100 \times 50 \times 15 \times 1.4$ & two & ISOWOOL 1000 \\
\hline \multirow{2}{*}{ effect of insulation } & $100 \times 50 \times 15 \times 1.4$ & one & ISOWOOL1000 \\
\hline & $100 \times 50 \times 15 \times 1.4$ & one & ROCKFIBRE \\
\hline \multirow{4}{*}{ effect of flange } & $100 \times 35 \times 15 \times 1.4$ & one & ISOWOOL1000 \\
\hline & $100 \times 50 \times 15 \times 1.4$ & one & ISOWOOL1000 \\
\hline & $100 \times 75 \times 15 \times 1.4$ & one & ISOWOOL1000 \\
\hline & $100 \times 100 \times 14 \times 1.4$ & one & ISOWOOL1000 \\
\hline $\begin{array}{l}\text { space between steel sections } \\
\text { from } 300 \text { to } 900 \mathrm{~mm}\end{array}$ & $100 \times 50 \times 15 \times 1.4$ & one & ISOWOOL1000 \\
\hline
\end{tabular}

Figure 9 shows temperature distribution in the panel with two steel studs and shows that even when the steel section spacing is $300 \mathrm{~mm}$, the panel temperature distribution becomes uniform at a short distance from the steel studs. Thus, an effective width of the panel can be defined, beyond which there is no heat transfer in the panel width direction. In addition, Figure 10 compares the average temperatures in the flanges for different spacing between the steel sections, which shows that the different spacing have no influence on the steel temperatures. Therefore, in the study to follow, the spacing between the steel sections is fixed at 300 $\mathrm{mm}$. 
The main interest of the parametric study is to find out the effective panel width (within which the effects of heat transfer in the panel width direction should be included) that will be used when calculating the weighted average of thermal resistances. Figure 11 shows the dependency of this effective panel width (given as the sum of $T_{i}$ and $B_{i}$ in the vertical axis) on different design parameters. It clearly shows that this width is noticeably influenced by the flange width, but is almost constant when changing other parameters. To confirm the effects of flange width, Figure 12 shows temperature distributions in the wall panels by using different flange widths and how the effective panel width is determined.

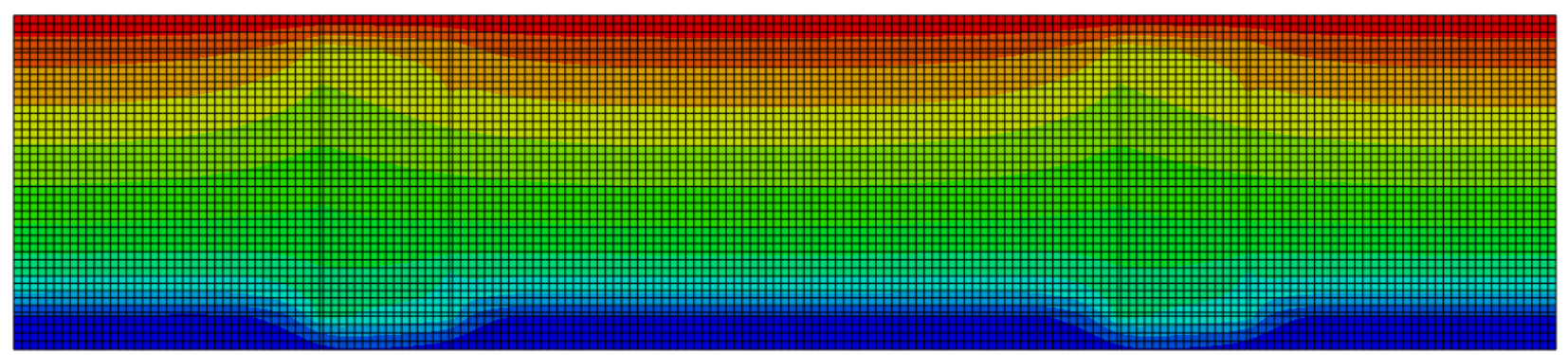

Figure 9. Temperature distribution for panel with two channel studs with $300 \mathrm{~mm}$ centre to centre distance

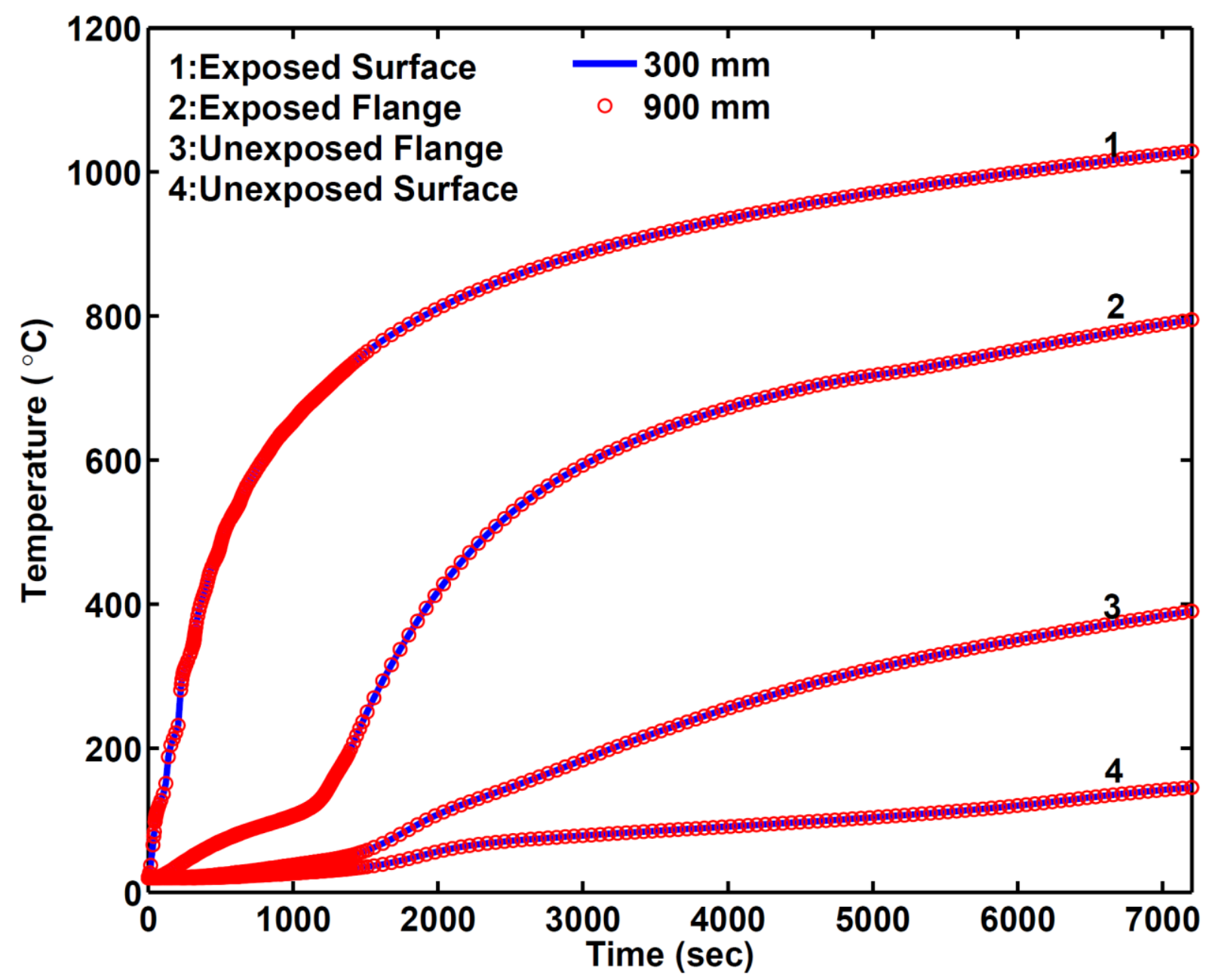

Figure 10. Surface and average steel temperatures in panels with two channel studs $(100 \times 50 \times 15 \times 1.4)$ and steel stud spacings of $300 \mathrm{~mm}$ to $900 \mathrm{~mm}$ 


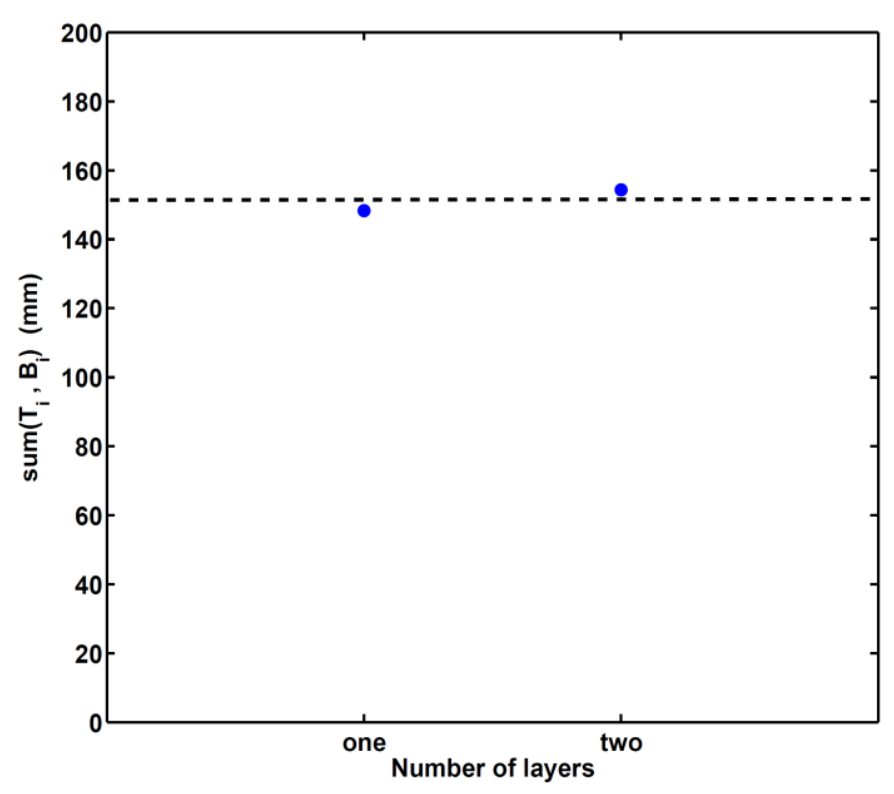

(a) effect of number of gypsum layers

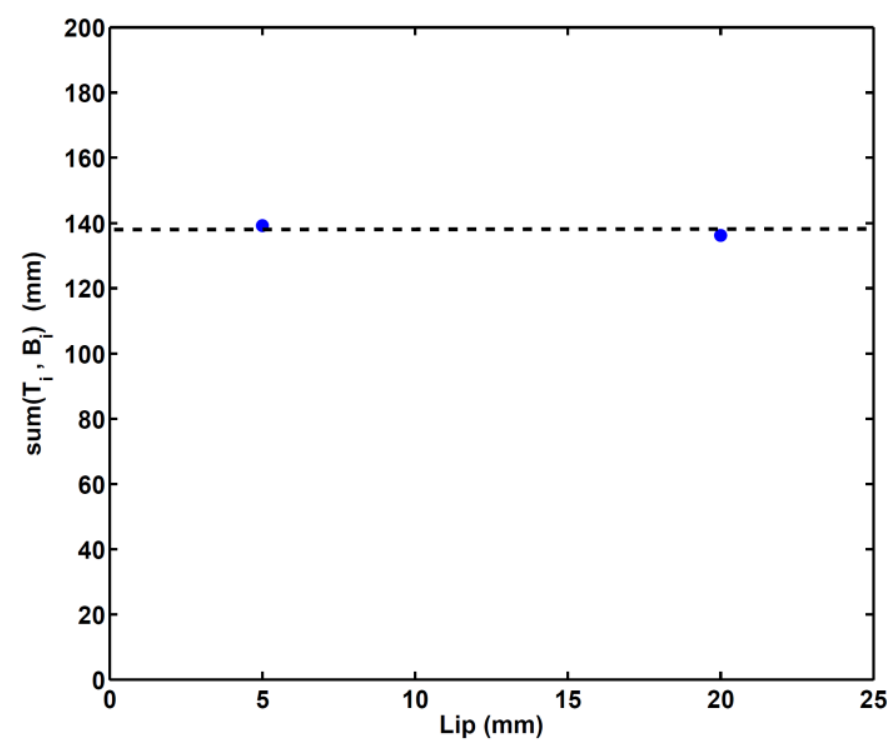

(c) effect of lip length

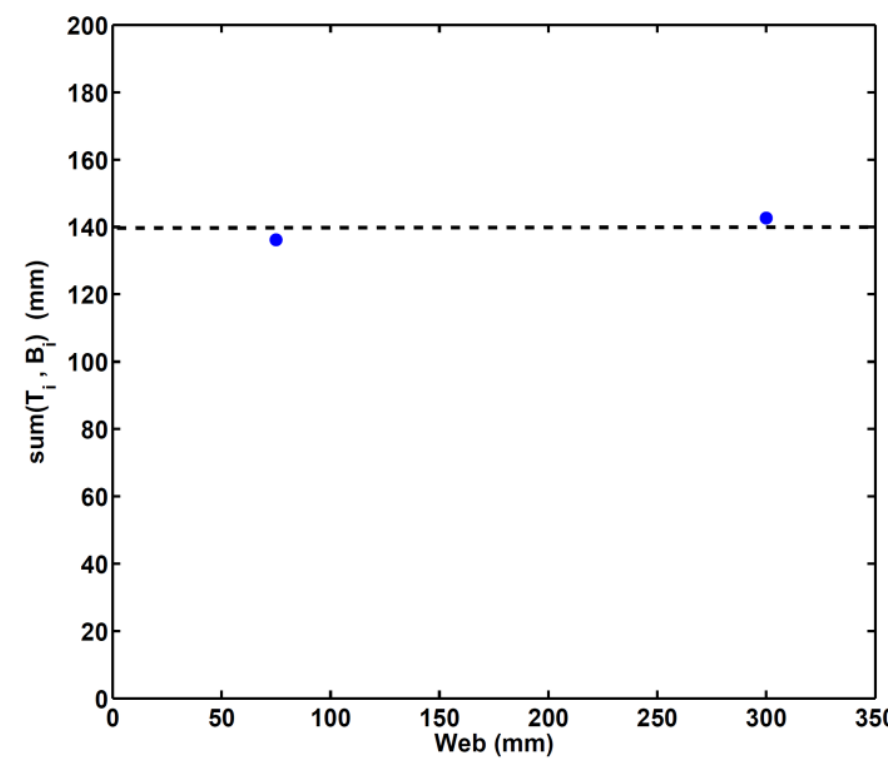

(e) effect of web depth

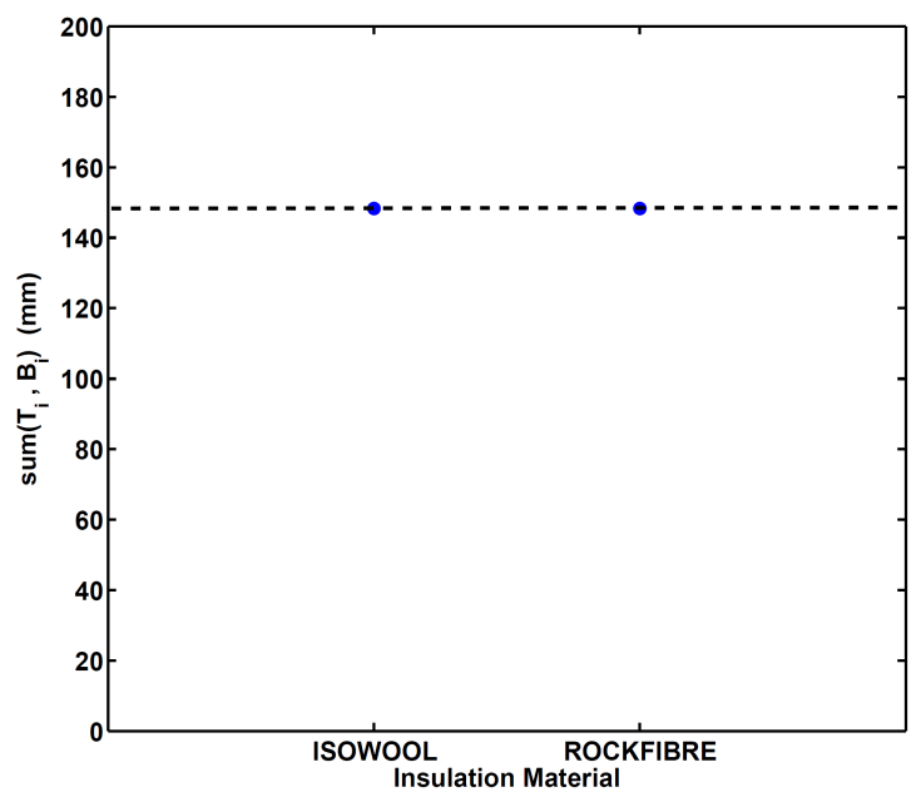

(b) effect of thermal insulation

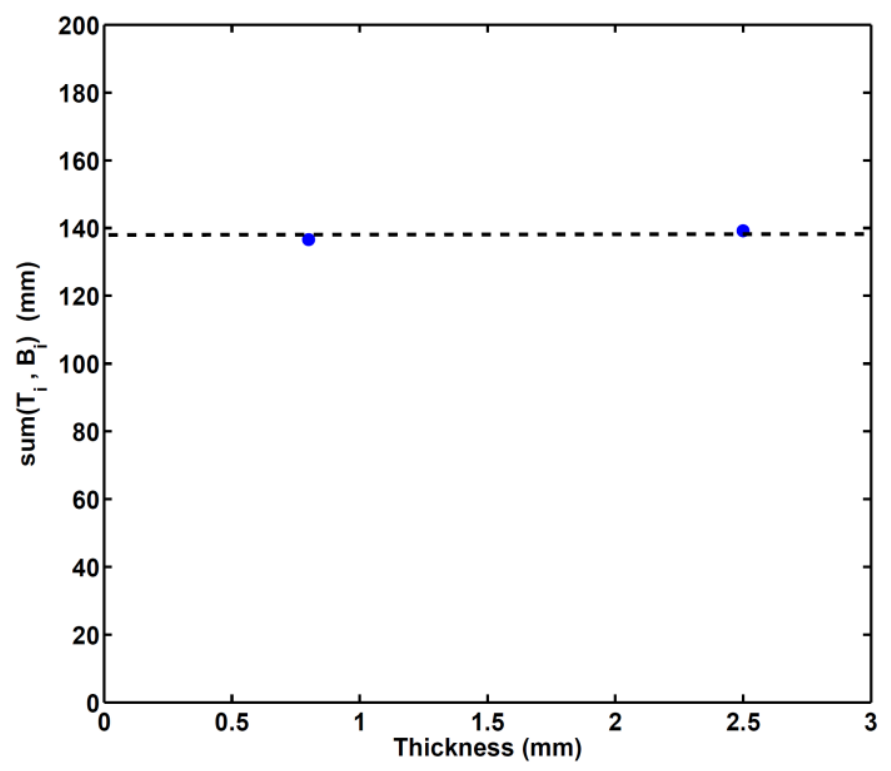

(d) effect of section thickness

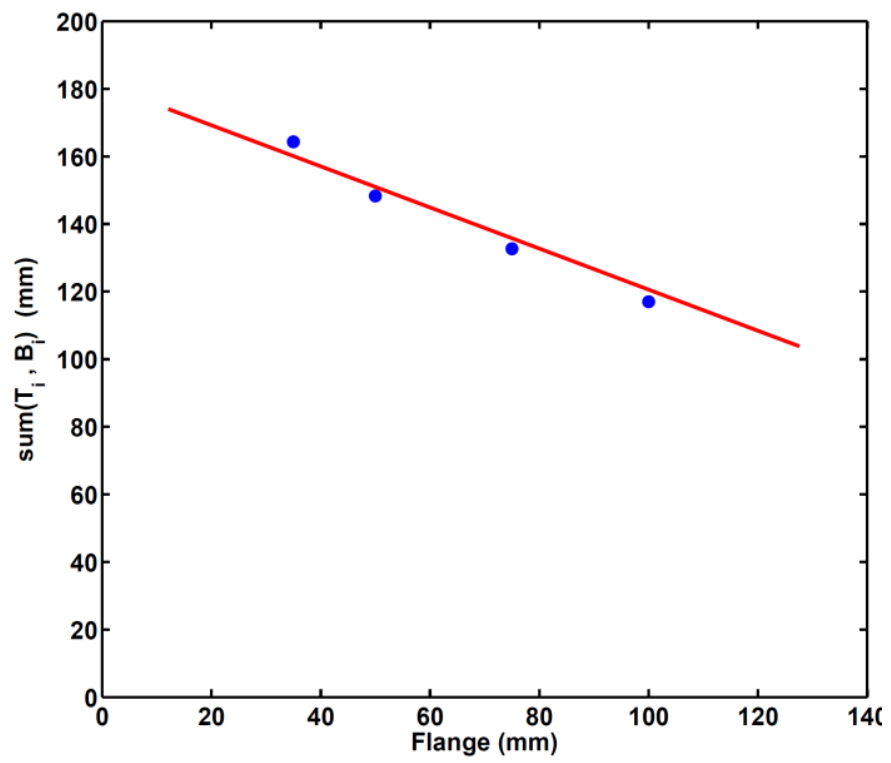

(f) effect of flange width

Figure 11. Dependency of effective panel width on different parameters (Ti and Bi are the distances from the two sides of the steel section with which it is assumed there is heat transfer in the panel width direction, see also Figures 12 and 17) 

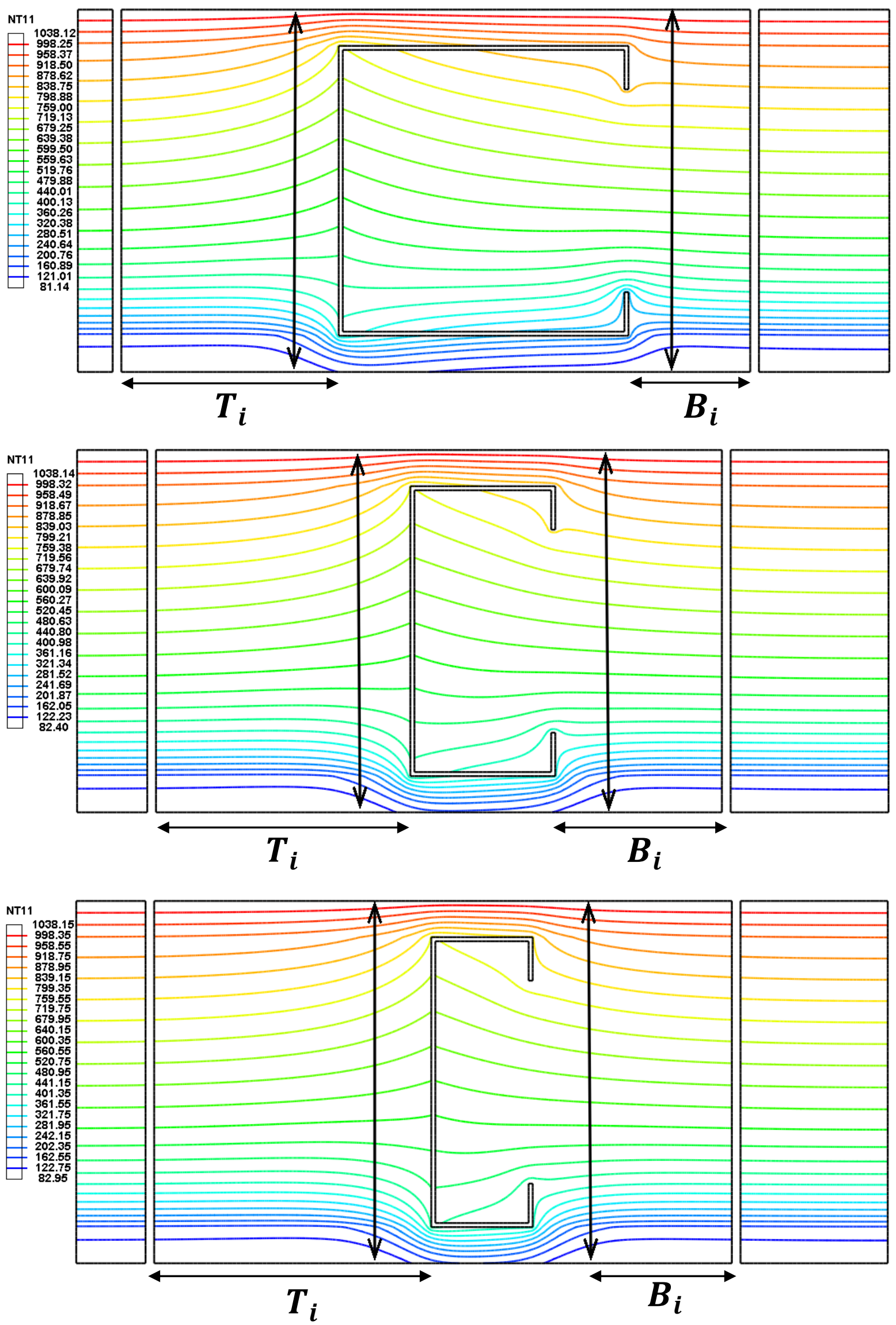

Figure 12. Temperature distributions for different flange widths and determination of effective panel width 
The remaining of the paper will determine the effective panel width for calculating the weighted average of thermal resistances. Table 3 lists the cases considered.

Table 3. Parametric study models

\begin{tabular}{ccc}
\hline Steel stud dimension* & $\begin{array}{c}\text { Number of gypsum } \\
\text { board layers** }\end{array}$ & $\begin{array}{c}\text { Type of thermal } \\
\text { insulation }\end{array}$ \\
\hline $75 \times 50 \times 15 \times 2.5$ & one & ISOWOOL1000 \\
$100 \times 50 \times 5 \times 1.4$ & one & ISOWOOL1000 \\
$100 \times 50 \times 15 \times 2.5$ & one & ISOWOOL1000 \\
$100 \times 50 \times 15 \times 0.8$ & one & ISOWOOL1000 \\
$100 \times 100 \times 15 \times 1.4$ & one & ISOWOOL1000 \\
$100 \times 35 \times 15 \times 1.4$ & one & ISOWOOL1000 \\
$75 \times 50 \times 15 \times 1.4$ & one & ISOWOOL1000 \\
$100 \times 75 \times 15 \times 0.8$ & one & ISOWOOL1000 \\
$100 \times 75 \times 15 \times 0.8$ & two & ISOWOOL1000 \\
$100 \times 35 \times 15 \times 1.4$ & two & ISOWOOL1000 \\
$100 \times 50 \times 15 \times 0.8$ & two & ISOWOOL1000 \\
$100 \times 50 \times 15 \times 1.4$ & one & ROCKFIBRE \\
$75 \times 50 \times 15 \times 2.5$ & one & ROCKFIBRE \\
$75 \times 50 \times 15 \times 1.4$ & one & ROCKFIBRE \\
\hline
\end{tabular}

* web depth $\mathrm{x}$ flange width $\mathrm{x}$ lip length $\mathrm{x}$ thickness

$* *$ thickness of one layer of gypsum board $=12.5 \mathrm{~mm}$ 


\section{Proposed approach for calculating temperature through wall panel assemblies}

In the simplified method, heat transfer in the wall panel cross-section is assumed to be one dimensional in the thickness direction. Figure 13 shows a wall panel which has been divided into 13 layers: 4 layers in the gypsum plasterboards on each side, 5 layers in the steel section. Two boundary layers, one on the fire side and one on the ambient temperature side, complete the heat transfer analysis system shown in Figure 13. For one layer, the following heat balance equation may be written:

$$
\left(\begin{array}{c}
\text { heat } \\
\text { entering } \\
\text { the layer }
\end{array}\right)-\left(\begin{array}{c}
\text { heat } \\
\text { leaving } \\
\text { the layer }
\end{array}\right)=\left(\begin{array}{c}
\text { heat change } \\
\text { to change layer } \\
\text { temperature }
\end{array}\right)
$$

Over a small time interval, the heat transfer between any two layers can be generally written as:

$$
\dot{\mathrm{Q}}=\frac{\Delta \mathrm{T}}{\Sigma \mathrm{R}}
$$

Where $\Delta \mathrm{T}$ is the temperature difference between these two layers and $\Sigma \mathrm{R}$ is the total thermal resistance in the heat transfer path.

The amount of heat required to change the temperature of a layer is:

$$
\dot{\mathrm{Q}}=\Sigma \mathrm{R}_{\text {capacity }} \frac{\mathrm{dT}}{\mathrm{dt}}
$$

Where $\mathrm{t}$ is time and $\Sigma \mathrm{R}_{\text {capacity }}$ is the total heat capacitance (mass times specific heat) of the layer.

In this study, the thermal resistance is calculated using the weighted average of the materials within the heat transfer path. Details are as follows:

- For heat transfer between the fire and the slice of gypsum board on the fire exposed side (point 1), the thermal resistance is the total of the thermal boundary layer and $1 / 2$ of the gypsum slice;

- For heat conduction between two adjacent gypsum slices (points 2-3, 3-4, 4-5, 10-11, 11-12 and 1213 ), the thermal resistance is the total of the 2 halves each slice;

- For heat transfer between the slice of gypsum board on the air side with the air layer, the thermal resistance is the total of the air layer and $1 / 2$ of the gypsum slice (point 14);

- For heat transfer between a gypsum slice and a steel slice or between a two adjacent steel slices, calculation of the total thermal resistance should include different materials that form the slices. Figure 14 shows the materials that should be included in the total thermal resistance for heat transfer between slices 5-10. For each slice, the thermal resistances are in parallel. Therefore, the thermal resistance should be calculated using $\frac{1}{R_{\text {total }}}=\frac{1}{R_{1}}+\frac{1}{R_{2}}+\cdots+\frac{1}{R_{n}}$ where $n$ is the layer of thermal resistances in parallel.

- To calculate the heat capacitance of each slice, all the materials within that slice should be included. Slices 2-4 and 11-13 consist of gypsum plasterboard only. Slices 5 and 10 consist of gypsum, steel and insulation. Slices 6-9 consist of different materials within each slice. Figure 14 shows the parallel heat resistance terms and Figure 15 shows the thermal capacitance terms for different multimaterial slices. 


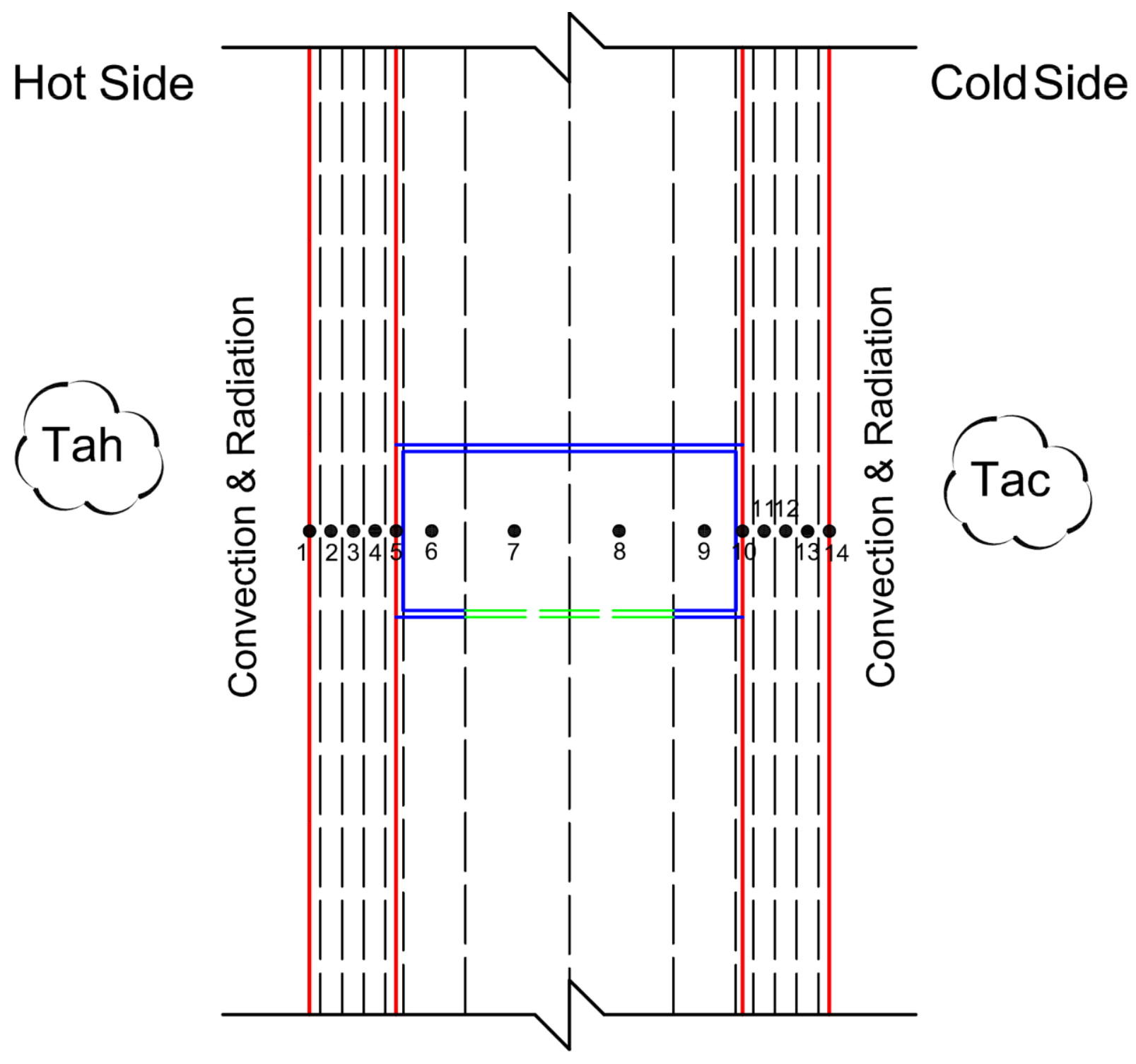

Figure 13. Proposed 1-D model

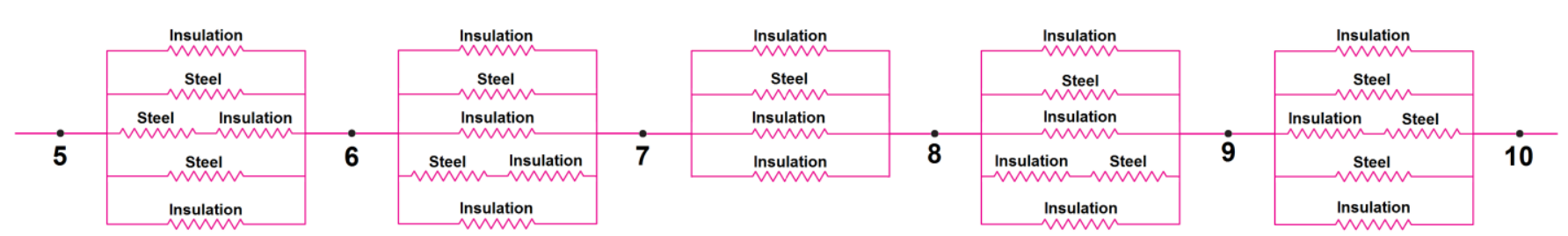

Figure 14. Heat resistance from point 5 to 10 


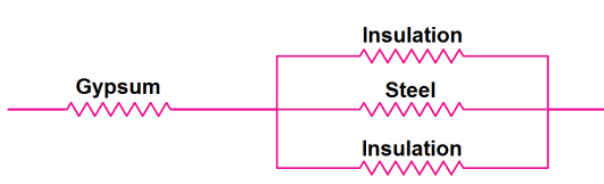

(5)

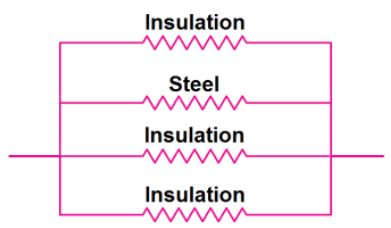

(8)

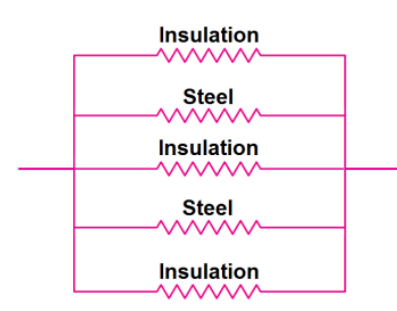

(6)

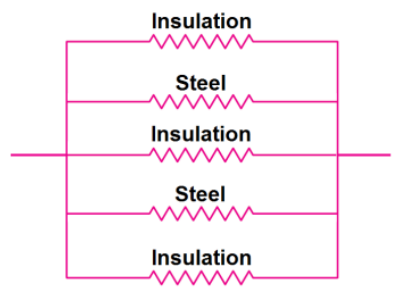

(9)

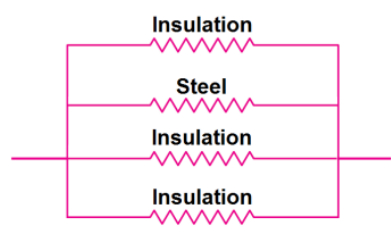

(7)

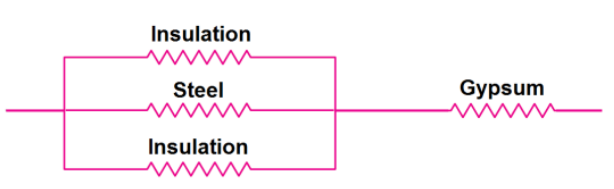

(10)

Figure 15. Heat capacitance for each slice of the panel

Appendix A gives detailed heat balance equations for all the slices shown in Figure 13. To calculate the thermal resistance and heat capacitance, it is necessary to determine the effective width of the panel that should be included in the calculations. Figure 16 shows the two extreme cases. Model \#1 includes the entire panel width between two steel sections and Model \#2 only considers the width of the panel being equal to the flange width. Model \#1 assumes heat transfer in the entire width of the panel and Model \#2 assumed no heat transfer in that direction. Model \#1 will over-predict temperatures in the steel flange on the exposed side and under-predict temperature in the steel flange on the unexposed side. Model \#2 will have opposite trends.

The correct panel width to be used will be in between these two extreme values. From examination of the results of this parametric study, refer to Figure 17, the effective width of the panel $\left(\mathrm{W}_{\mathrm{e}}\right)$, used for calculating the weighted average of thermal resistances is approximately the flange width $\left(b_{f}\right)$ plus $15 \%$ of the net width between the steel section and two edges of a $300 \mathrm{~mm}$ block $\left(300-\mathrm{b}_{\mathrm{f}}\right.$, in $\left.\mathrm{mm}\right)$. In other words:

$$
\mathrm{W}_{\mathrm{e}}=\mathrm{t}_{\mathrm{i}}+\mathrm{b}_{\mathrm{f}}+\mathrm{b}_{\mathrm{i}}=0.15\left(\mathrm{~T}_{\mathrm{i}}+\mathrm{B}_{\mathrm{i}}\right)+\mathrm{b}_{\mathrm{f}}=0.15\left(300-\mathrm{b}_{\mathrm{f}}\right)+\mathrm{b}_{\mathrm{f}}=45+0.85 \mathrm{~b}_{\mathrm{f}} \quad \text { (in mm) }
$$

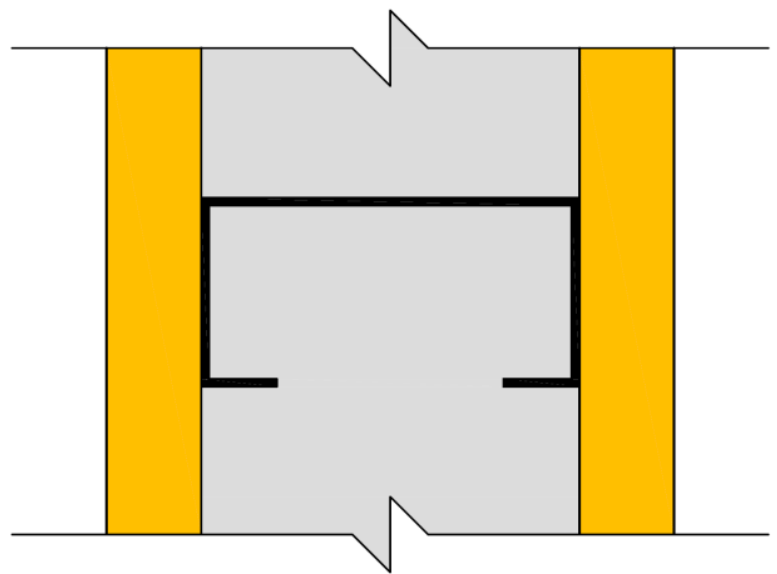

(a) Model \#1

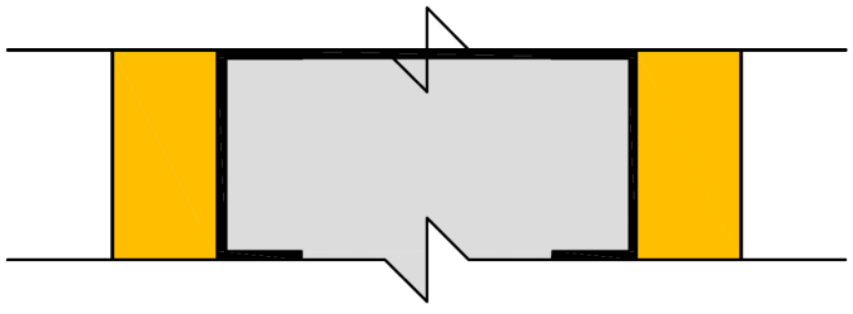

(b) Model \#2

Figure 16. Two possible models of panel width: (a) whole panel and (b) steel flange only 


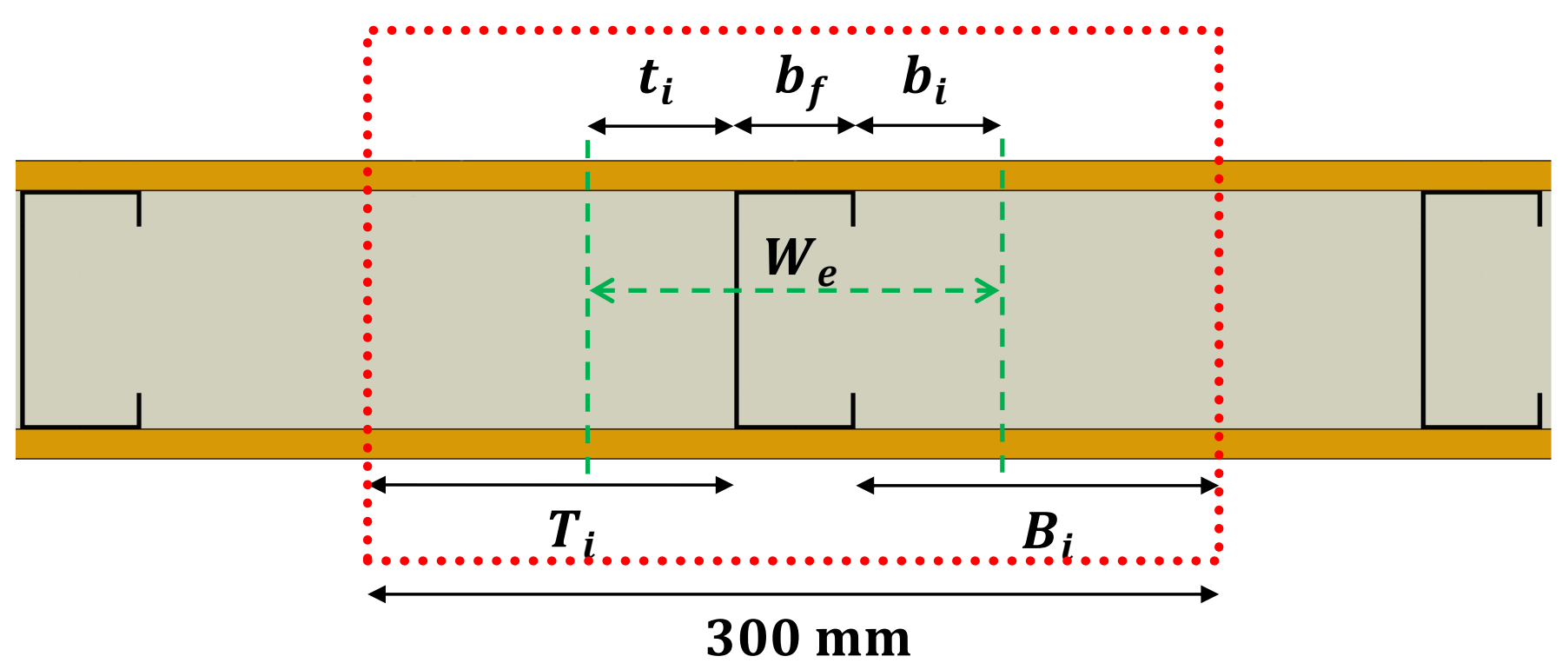

Figure 17. Proposed geometry for heat transfer calculaion

Figure 18 shows typical comparisons between ABAQUS simulation results and results from the proposed method using the three different panel widths shown in Figure 16 and 17. The parametric cases chosen represent two extremes, one with high steel thickness in combination with shallow panel depth (low heat transfer in panel width direction) and one with small steel thickness in combination with deep panel depth (high heat transfer in panel width direction). Results for other parametric study cases are between these two extremes. In both figures, using Model \#1 increases thermal resistance and produces higher steel temperature on the exposed side and lower temperature on the unexposed side. Using Model \#2 produces opposite trends. By using the proposed panel width for calculating the weighted average of thermal resistances, the proposed temperature calculation method gives both steel flange temperatures that are in very good agreement with the ABAQUS simulation results. Furthermore, since the purpose of the temperature calculation method is for calculating panel strength, higher inaccuracies can be tolerated on the cold side because the steel mechanical properties do not change much at these lower temperature levels. 


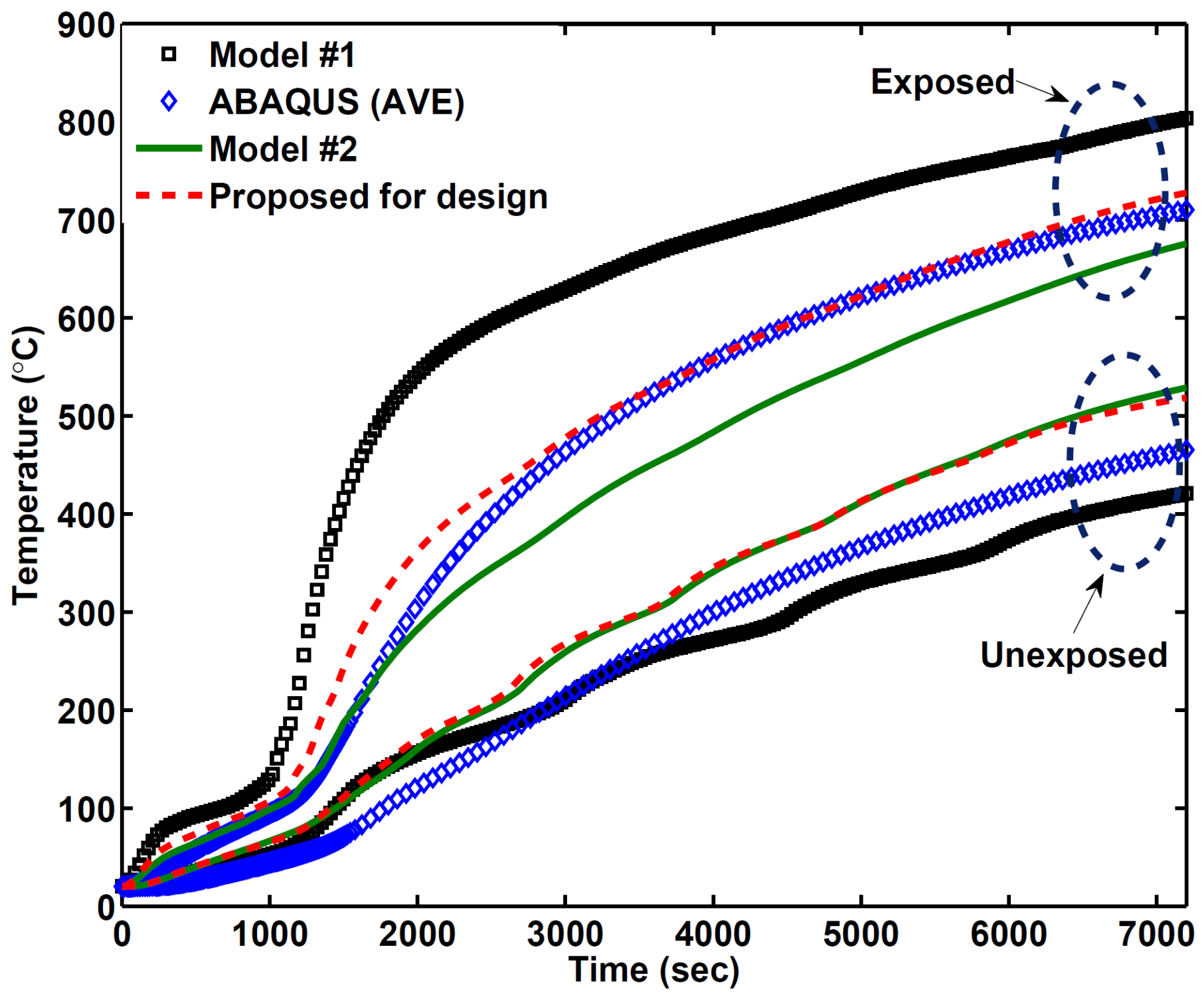


(a) $75 \times 50 \times 15 \times 2.5$ - one layer - ISOWOOL1000

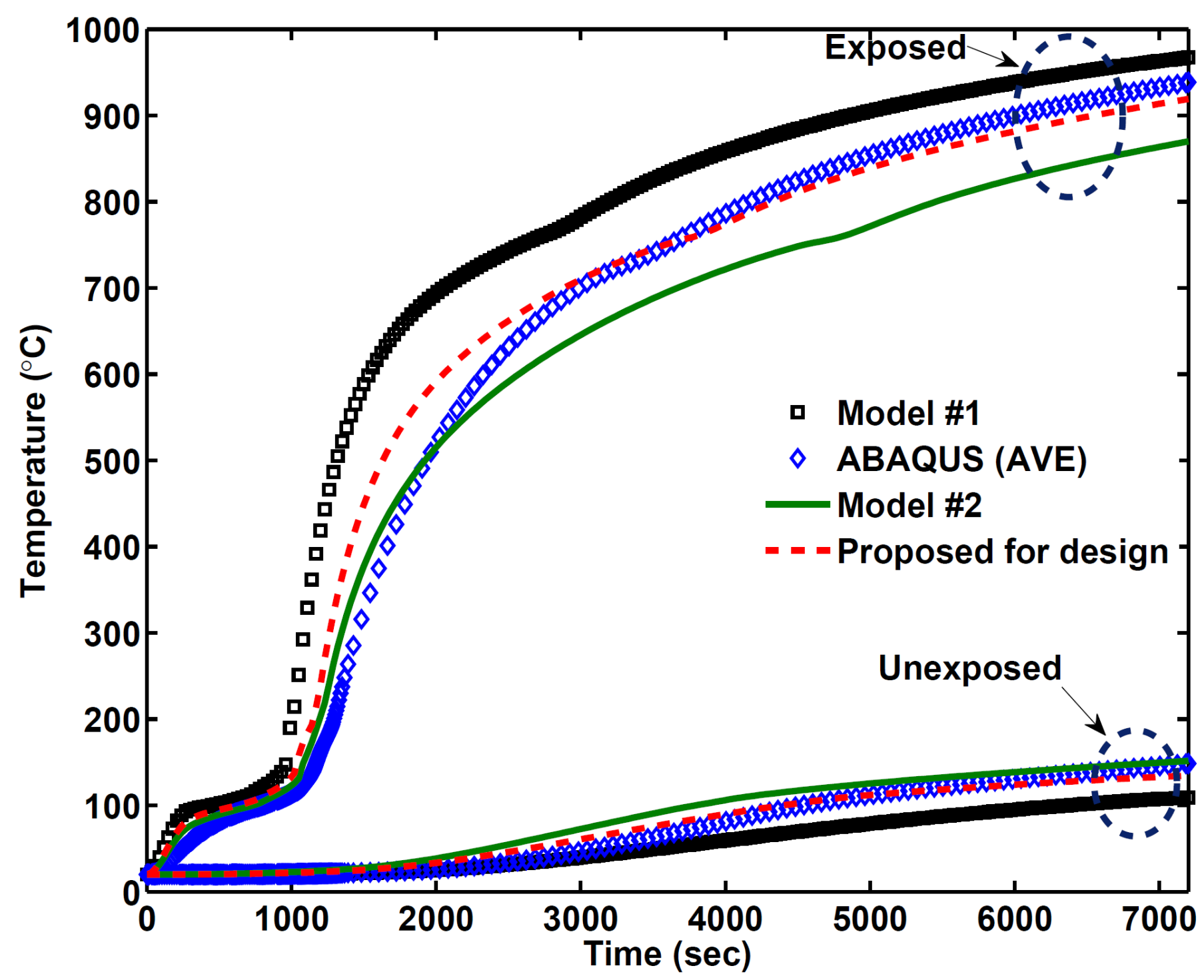

(b) 300x50x15x0.8 - one layer - ISOWOOL1000

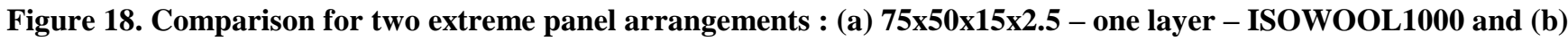
$300 \times 50 \times 15 \times 0.8$ - one layer - ISOWOOL1000 


\section{Comparing fire resistance of steel studs by using the proposed approach and ABAQUS for heat}

\section{transfer}

To check accuracy of the proposed approach for calculating compressive load-bearing capacity of the steel studs, structural analysis was carried out using temperature profiles generated using ABAQUS heat transfer and using the proposed method. The structural analysis models were built using ABAQUS. The 14 temperature parametric cases in Table 3 were included, each at five load ratios of 0.3, 0.4, 0.5, 0.6 and 0.7. In total, 140 ABAQUS simulations were made. The mechanical properties used in these models are: steel yield stress $350 \mathrm{~N} / \mathrm{mm}^{2}$, elastic modulus $205,000 \mathrm{~N} / \mathrm{mm}^{2}$, thermal expansion coefficient of $0.000014 /{ }^{\circ} \mathrm{C}$. The elevated temperature stress-strain relationships of steel were based on EN 1993-1-2 [10].

For ABAQUS structural analysis, uniform temperature distributions were assumed in both flanges and linear distribution in the web, the average temperatures being obtained from either ABAQUS heat transfer or the proposed approach. The steel stud was $3000 \mathrm{~mm}$ in height and simply supported at both the top and the bottom ends. Lateral restraints (in the plane of the flange) were applied at $300 \mathrm{~mm}$ intervals along the stud length to simulate connections to gypsums, which prevented torsional buckling. The ABAQUS simulation model was the same as previously used by the authors [1-3], including the following main features: shell element type S4, mesh size $2.5 \mathrm{~mm}$, initial imperfection according to the first buckling mode, mechanical load applied first then maintained constant while increasing the temperature. Table 4 and Figure 19 compare the fire resistance times between using the two methods of calculating steel temperatures. 
Table 4. Comparison of fire resistance results

\begin{tabular}{|c|c|c|c|c|c|}
\hline Model & $\begin{array}{l}\text { Load } \\
\text { Ratio }\end{array}$ & $\begin{array}{l}\text { Appli } \\
\text { ed } \\
\text { Load } \\
(\mathrm{kN})\end{array}$ & $\begin{array}{l}\text { Input temperature from } \\
\text { proposed approach } \\
\text { (min) }\end{array}$ & $\begin{array}{l}\text { Input temperature from ABAQUS } \\
\text { heat transfer } \\
(\mathrm{min})\end{array}$ & $\begin{array}{l}\text { Differe } \\
\text { nce } \\
\text { ratio } \\
(\%)\end{array}$ \\
\hline \multirow{5}{*}{$\begin{array}{c}75 \times 50 \times 15 \times 2.5 \text {-onelayer- } \\
\text { isowool }\end{array}$} & 0.30 & 27.00 & 59.82 & 58.76 & -1.80 \\
\hline & 0.40 & 36.00 & 35.89 & 39.31 & 8.69 \\
\hline & 0.50 & 45.00 & 27.05 & 31.14 & 13.14 \\
\hline & 0.60 & 54.00 & 23.58 & 22.18 & -6.32 \\
\hline & 0.70 & 63.00 & 20.95 & 22.04 & 4.92 \\
\hline \multirow{5}{*}{$\begin{array}{c}100 \times 50 \times 15 \times 2.5 \text {-onelayer- } \\
\text { isowool }\end{array}$} & 0.30 & 43.80 & 65.35 & 63.61 & -2.73 \\
\hline & 0.40 & 58.40 & 38.59 & 42.85 & 9.95 \\
\hline & 0.50 & 73.00 & 27.89 & 32.53 & 14.27 \\
\hline & 0.60 & 87.60 & 23.56 & 26.28 & 10.34 \\
\hline & 0.70 & 102.2 & 20.68 & 23.04 & 10.25 \\
\hline \multirow{5}{*}{$\begin{array}{c}100 \times 50 \times 15 \times 0.8 \text {-onelayer- } \\
\text { isowool }\end{array}$} & 0.30 & 8.10 & 40.57 & 41.38 & 1.96 \\
\hline & 0.40 & 10.80 & 27.24 & 30.93 & 11.93 \\
\hline & 0.50 & 13.50 & 21.41 & 24.90 & 14.01 \\
\hline & 0.60 & 16.20 & 19.23 & 22.18 & 13.33 \\
\hline & 0.70 & 18.90 & 17.80 & 19.75 & 9.87 \\
\hline \multirow{5}{*}{$\begin{array}{c}100 \times 35 \times 15 \times 1.4 \text {-onelayer- } \\
\text { isowool }\end{array}$} & 0.30 & 15.60 & 66.23 & 59.78 & -10.79 \\
\hline & 0.40 & 20.80 & 40.68 & 42.22 & 3.63 \\
\hline & 0.50 & 26.00 & 28.08 & 31.82 & 11.73 \\
\hline & 0.60 & 31.20 & 23.14 & 25.95 & 10.84 \\
\hline & 0.70 & 36.40 & 20.64 & 25.10 & 17.76 \\
\hline \multirow{5}{*}{$\begin{array}{c}100 \times 50 \times 5 \times 1.4 \text {-onelayer- } \\
\text { isowool }\end{array}$} & 0.30 & 13.50 & 65.29 & 61.66 & -5.87 \\
\hline & 0.40 & 18.00 & 42.59 & 44.67 & 4.65 \\
\hline & 0.50 & 22.50 & 28.95 & 33.80 & 14.35 \\
\hline & 0.60 & 27.00 & 23.25 & 27.53 & 15.54 \\
\hline & 0.70 & 31.50 & 20.73 & 24.02 & 13.70 \\
\hline \multirow{5}{*}{$\begin{array}{l}100 \times 50 \times 15 \times 0.8- \\
\text { twolayers-isowool }\end{array}$} & 0.30 & 8.10 & 107.01 & 91.18 & -17.36 \\
\hline & 0.40 & 10.80 & 71.45 & 71.70 & 0.35 \\
\hline & 0.50 & 13.50 & 59.83 & 66.45 & 9.96 \\
\hline & 0.60 & 16.20 & 54.18 & 55.77 & 2.85 \\
\hline & 0.70 & 18.90 & 49.56 & 50.99 & 2.79 \\
\hline \multirow{5}{*}{$\begin{array}{l}100 \times 35 \times 15 \times 1.4- \\
\text { twolayers-isowool }\end{array}$} & $0.30 *$ & 15.60 & - & - & - \\
\hline & 0.40 & 20.80 & 105.38 & 89.40 & -17.87 \\
\hline & 0.50 & 26.00 & 71.63 & 71.37 & -0.37 \\
\hline & 0.60 & 31.20 & 61.15 & 62.67 & 2.41 \\
\hline & 0.70 & 36.40 & 55.78 & 56.15 & 0.66 \\
\hline \multirow{5}{*}{$\begin{array}{c}100 \times 50 \times 15 \times 1.4 \text {-onelayer- } \\
\text { rockfibre }\end{array}$} & 0.30 & 18.60 & 58.26 & 68.87 & 15.40 \\
\hline & 0.40 & 24.80 & 40.36 & 47.97 & 15.85 \\
\hline & 0.50 & 31.00 & 27.78 & 32.52 & 14.57 \\
\hline & 0.60 & 37.20 & 22.64 & 25.45 & 11.02 \\
\hline & 0.70 & 43.40 & 19.89 & 21.47 & 7.38 \\
\hline \multirow{5}{*}{$\begin{array}{c}75 \times 50 \times 15 \times 2.5 \text {-onelayer- } \\
\text { rockfibre }\end{array}$} & 0.30 & 27.00 & 63.67 & 75.93 & 16.15 \\
\hline & 0.40 & 36.00 & 39.44 & 47.90 & 17.66 \\
\hline & 0.50 & 45.00 & 29.28 & 34.93 & 16.18 \\
\hline & 0.60 & 54.00 & 24.48 & 25.58 & 4.29 \\
\hline & 0.70 & 63.00 & 21.33 & 22.29 & 4.29 \\
\hline \multirow{5}{*}{$\begin{array}{c}75 \times 50 \times 15 \times 1.4 \text {-onelayer- } \\
\text { rockfibre }\end{array}$} & 0.30 & 16.20 & 35.94 & 41.56 & 13.51 \\
\hline & 0.40 & 21.60 & 26.50 & 30.22 & 12.30 \\
\hline & 0.50 & 27.00 & 22.11 & 24.59 & 10.05 \\
\hline & 0.60 & 32.40 & 19.72 & 21.06 & 6.37 \\
\hline & 0.70 & 37.80 & 15.00 & 13.66 & -9.75 \\
\hline \multirow{4}{*}{$\begin{array}{c}75 \times 50 \times 15 \times 1.4 \text {-onelayer- } \\
\text { isowool }\end{array}$} & 0.30 & 16.20 & 32.65 & 35.11 & 7.01 \\
\hline & 0.40 & 21.60 & 24.57 & 27.88 & 11.87 \\
\hline & 0.50 & 27.00 & 21.40 & 23.77 & 9.97 \\
\hline & 0.60 & 32.40 & 19.34 & 20.85 & 7.24 \\
\hline
\end{tabular}




\begin{tabular}{|c|c|c|c|c|c|}
\hline & 0.70 & 37.80 & 16.57 & 14.16 & -17.03 \\
\hline \multirow{5}{*}{$\begin{array}{l}\text { 100x75x } 15 \times 0.8- \\
\text { twolayers-isowool }\end{array}$} & 0.30 & 7.20 & 96.71 & 87.52 & -10.51 \\
\hline & 0.40 & 9.60 & 68.67 & 68.82 & 0.22 \\
\hline & 0.50 & 12.00 & 59.10 & 58.87 & -0.38 \\
\hline & 0.60 & 14.40 & 55.05 & 54.30 & -1.39 \\
\hline & 0.70 & 16.80 & 50.58 & 49.41 & -2.35 \\
\hline \multirow{5}{*}{$\begin{array}{c}100 \times 75 \times 15 \times 0.8 \text {-onelayer- } \\
\text { isowool }\end{array}$} & 0.30 & 7.20 & 37.79 & 40.00 & 5.54 \\
\hline & 0.40 & 9.60 & 25.40 & 28.66 & 11.38 \\
\hline & 0.50 & 12.00 & 21.10 & 23.74 & 11.15 \\
\hline & 0.60 & 14.40 & 19.41 & 21.52 & 9.80 \\
\hline & 0.70 & 16.80 & 17.91 & 19.18 & 6.61 \\
\hline \multirow{7}{*}{$\begin{array}{l}\text { 100x100x15x1.4- } \\
\text { onelayer-isowool }\end{array}$} & 0.30 & 18.00 & 41.30 & 43.93 & 5.98 \\
\hline & 0.40 & 24.00 & 34.10 & 37.09 & 8.07 \\
\hline & 0.50 & 30.00 & 25.03 & 28.88 & 13.33 \\
\hline & 0.60 & 36.00 & 21.83 & 24.91 & 12.37 \\
\hline & 0.70 & 42.00 & 20.31 & 22.63 & 10.27 \\
\hline & & & & Average & 6.07 \\
\hline & & & & Standard deviation & 8.54 \\
\hline
\end{tabular}

*this model didn't fail until 120 minutes.

The fire resistance times calculated using the two different temperature calculation methods are very close. The average difference is $6 \%$ with the fire resistance results using the proposed temperature calculation method being on the safe side. The standard deviation is $8.54 \%$. This level of agreement is excellent, considering the easiness of implementing the proposed temperature calculation method and the complexity of the problem.

In the UK Steel Construction Institute's design guide P129 [14] for fire resistance of thin-walled steel structures, panels with one and two layers of fire resistance gypsum plasterboards on each side of the steel studs are accepted to be able to provide 30 and 60 minutes of standard fire resistance respectively. This recommendation does not seem safe in many cases. Particularly if one layer of gypsum is used, the fire resistance that can be achieved is below 30 minutes in many cases, even though the applied load level is within practical range. 


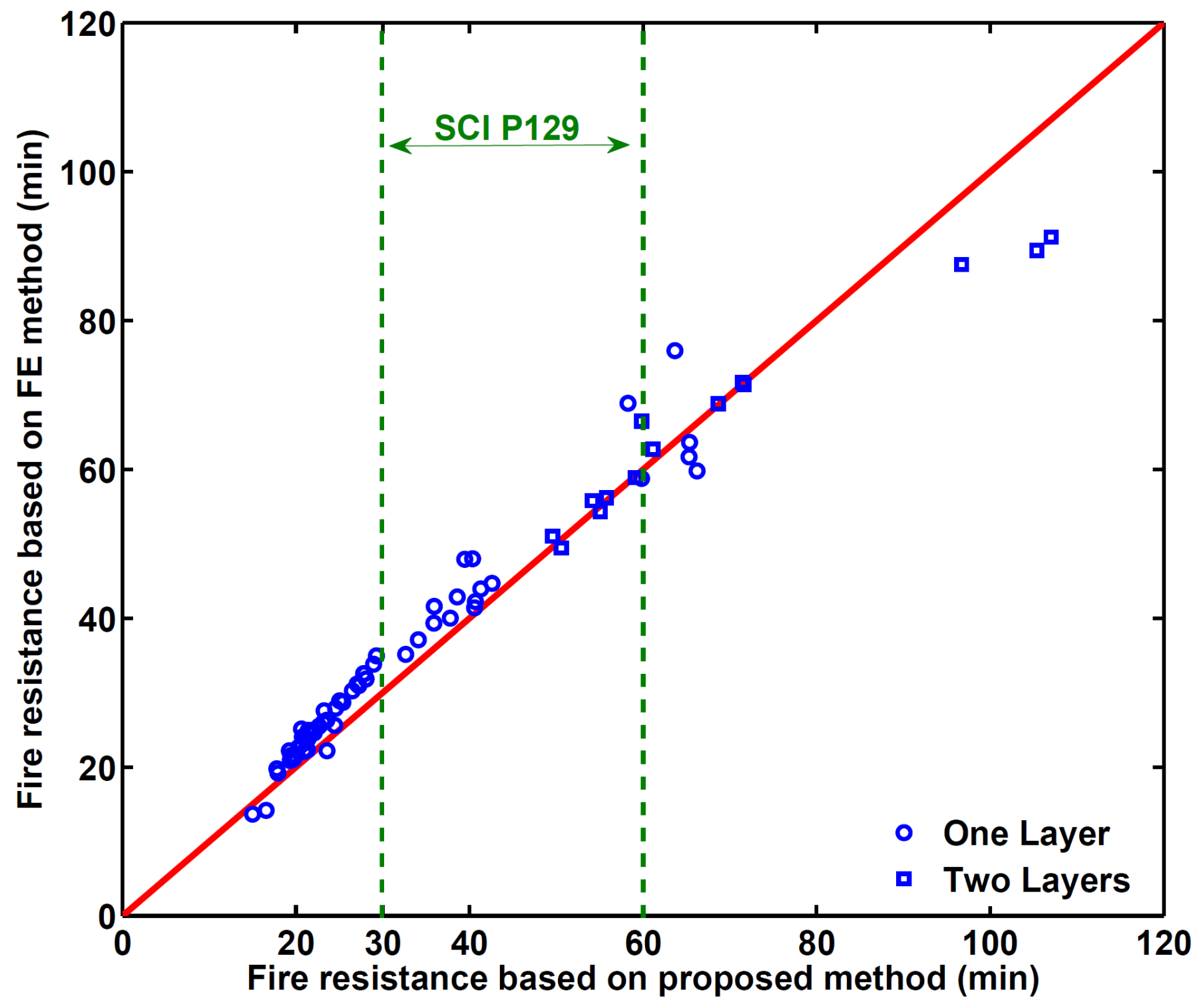

Figure 19. Comparison of fire resistance between using ABAQUS and proposed approach for calculating steel temperatures 


\section{Comparing fire resistance by using the proposed approach for heat transfer analysis and Direct}

\section{Strength Method for structural analysis and ABAQUS for both heat and structural analysis}

As mentioned earlier, the authors have recently developed a new design method for calculating the ultimate strength of thin-walled steel columns with non-uniform temperature distribution in the cross-sections. Details of this method have been separately presented in [1-3] for global, local and distortional buckling respectively. Together with the temperature calculation method proposed in this paper, a complete method is now available to calculate fire resistance of cold-formed thin-walled steel members under compression. The strength calculation method proposed by the authors is based on the Direct Strength Method [15]. In this method, the elastic critical buckling loads for local, distortional and global buckling as well as the plastic resistance of the column are calculated separately. They are then combined by using interaction equations to give the column design strength. For completeness, these interaction equations are reproduced below.

The axial strength of the column is the minimum of $P_{n e}, P_{n l}$ and $P_{n d}$ for the three buckling modes.

- For global buckling [1]:

$$
\begin{aligned}
& \lambda_{c}=\sqrt{\frac{P_{y}}{P_{\text {cre }}}} \\
\text { for } \lambda_{c} \leq 1.5, & P_{n e}=\left(0.495^{\lambda_{c}{ }^{2}}\right) P_{y} \\
\text { for } \lambda_{c}>1.5, & P_{n e}=\left(\frac{0.462}{\lambda_{c}{ }^{2}}\right) P_{y}
\end{aligned}
$$

- For local buckling (including local - global interaction) [2]:

$$
\begin{gathered}
\lambda_{l}=\sqrt{\frac{P_{n e}}{P_{c r l}}} \\
\text { for } \lambda_{l} \leq 0.776, \\
P_{n l}=P_{n e} \\
\text { for } \lambda_{l}>0.776, \quad P_{n l}=\left(1-0.22\left(\frac{P_{c r l}}{P_{n e}}\right)^{0.75}\right)\left(\frac{P_{c r l}}{P_{n e}}\right)^{0.75} P_{n e}
\end{gathered}
$$

- For distortional buckling [3]:

$$
\begin{gathered}
\lambda_{d}=\sqrt{\frac{P_{y}}{P_{c r d}}} \\
P_{n d}=P_{y} \\
\text { for } \lambda_{d} \leq 0.561, \\
\text { for } \lambda_{d}>0.561, \quad P_{n d}=0.65\left(1-0.14\left(\frac{P_{c r d}}{P_{y}}\right)^{0.7}\right)\left(\frac{P_{c r d}}{P_{y}}\right)^{0.7} P_{y}
\end{gathered}
$$

In the above equations: $P_{y}$ is the effective squash load of the cross-section; $P_{c r e}$ is the critical elastic global buckling load; $P_{c r d}$ is the critical elastic distortional buckling load; $P_{c r l}$ is the critical elastic local buckling 
load; $\lambda_{c}, \lambda_{d}$ and $\lambda_{l}$ are the slenderness for global, distortional and local buckling modes respectively; $P_{n e}$, $P_{n l}$ and $P_{n d}$ are the column axial strength for global, distortional and local buckling modes respectively.

Figure 20 shows the process of comparison. Figure 21 compares the column compressive resistances obtained from using the complete proposed design method with those using ABAQUS simulations for both heat transfer and structural analysis. The agreement is very good, with an overall average of 5.33\% and standard deviation of $14.44 \%$. Considering the complexity of the problem being dealt with and simplicity of the proposed design method, this level of accuracy is considered excellent and acceptable for design purpose.

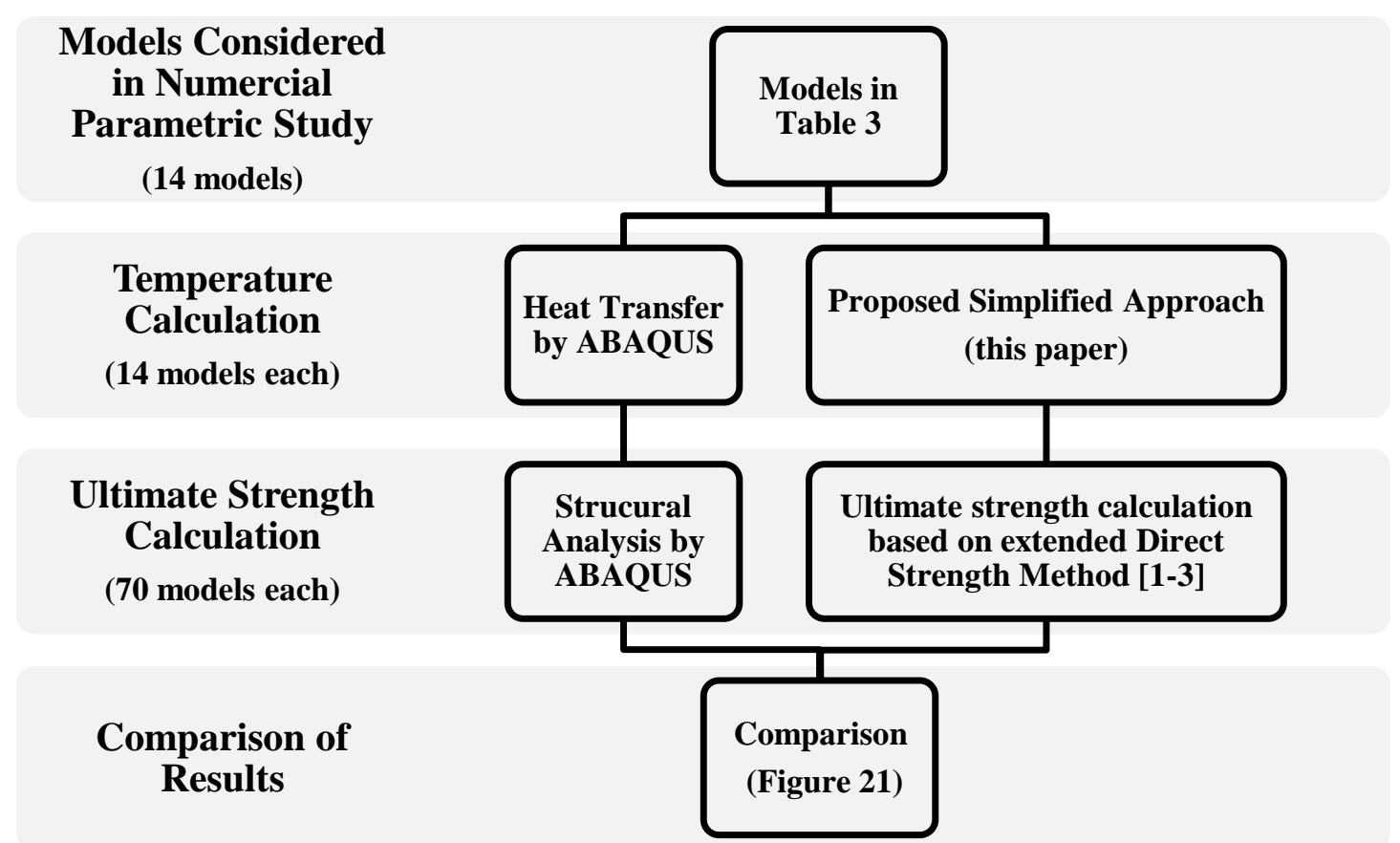

Figure 20. Process to compare results of ABAQUS simulation and simplified approach for temperature calculation (this paper) and Direct Strength Method [1-3] 


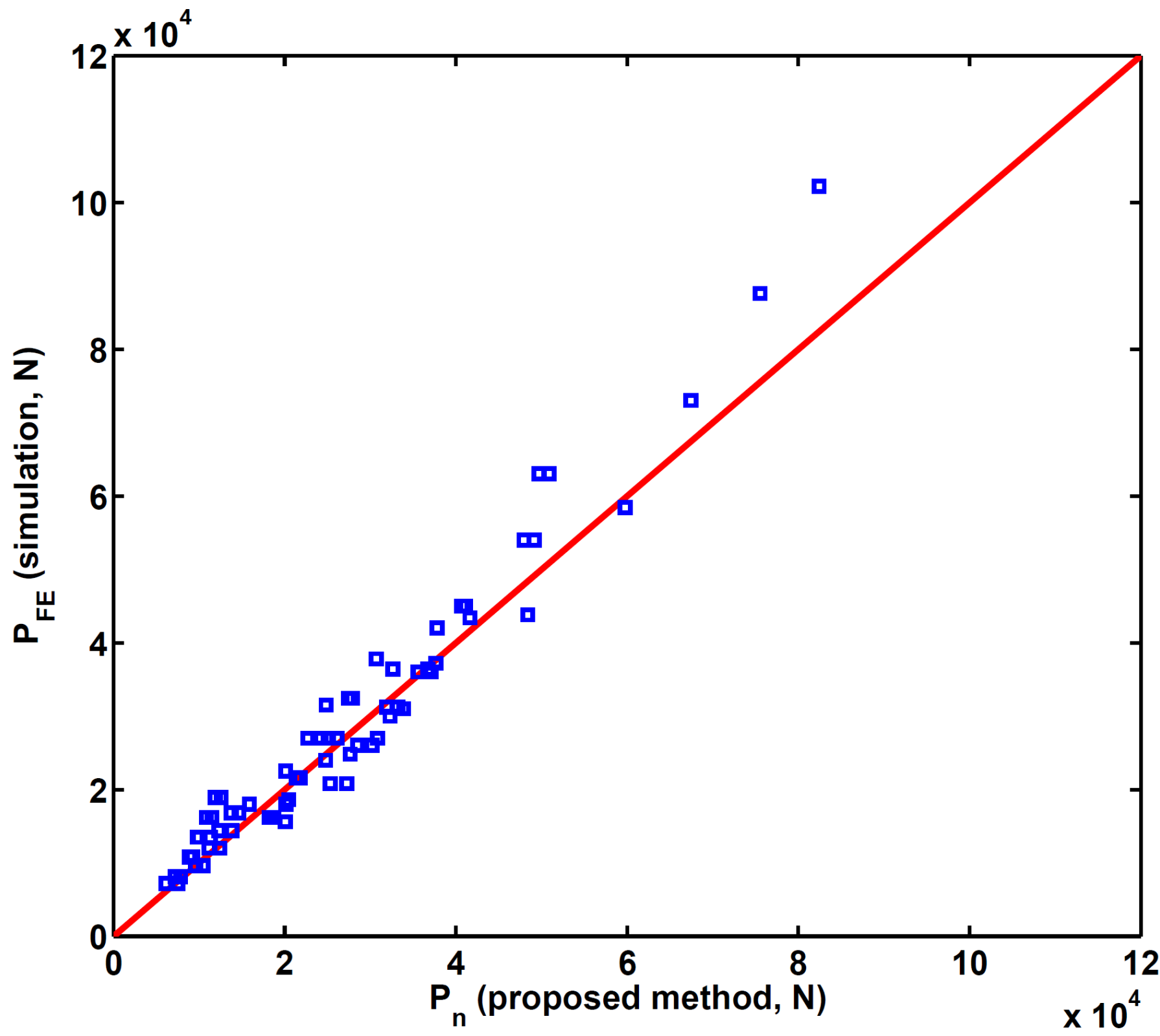

Figure 21. Accuarcy of ultimate strengths based on proposed approach 


\section{Conclusions}

This paper has presented the results of an extensive set of numerical simulation and analytical studies to investigate the accuracy of a proposed method for predicting temperature distribution in the steel section in wall panels exposed to fire from one side. This temperature distribution assumes uniform temperature in each flange and linear temperature distribution in the web between the two flanges. The proposed temperature calculation approach assumes heat transfer in the panel is one dimensional in the thickness direction of the panel. To calculate the weighted average of thermal resistances, the effective panel width can be taken as $45+0.85 b_{\mathrm{f}}$ (in $\mathrm{mm}$ ) where $\mathrm{b}_{\mathrm{f}}$ is the steel section flange width.

The proposed temperature calculation method is easy to implement and gives average flange temperatures that are in very good agreement with ABAQUS 2-dimensional Finite Element heat transfer results. Using steel temperatures from the proposed method and ABAQUS heat transfer analysis, and ABAQUS structural analysis, the calculated stud fire resistance times are in excellent agreement, the average being $6 \%$ for a very large range of different panel design parameters.

The proposed temperature calculation method can be combined with the authors' recent proposal for calculating steel stud global, local and distortional buckling capacities [1-3] as a practical design method. The stud fire resistance times calculated using this proposed design method are in very good agreement with using ABAQUS Finite Element package for both heat transfer and structural analysis. 


\section{Appendix A. Detailed heat balance equations}

Section 4 of this paper has explained the theory and assumptions of the simplified heat transfer analysis method based on heat balance at the few selected nodes. This appendix presents details of how this method has been implemented. Refer to Figures 13-15 in the main text for how the panel is divided into different segments each represented by a node.

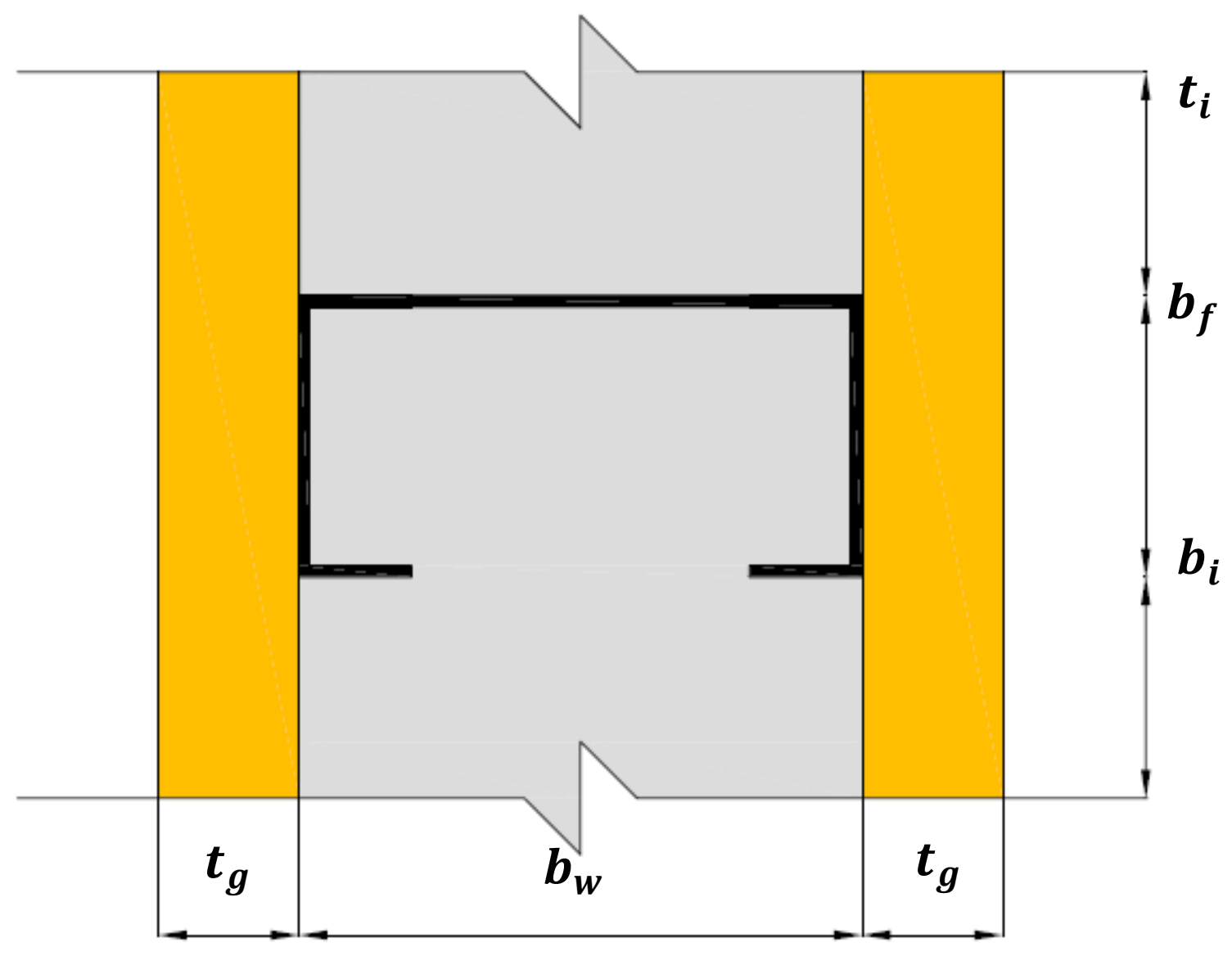

Figure A-1. Panel Geometry

a) Point 1 (exposed surface):

$$
\begin{gathered}
\dot{Q}_{l}-\dot{Q}_{\text {cond } 12}=\dot{Q}_{c a p 1} \\
h_{\text {convh }} * l *\left(T_{a h}-T_{1}\right)+\varepsilon_{h} * \sigma * l *\left(\left(T_{a h}+273.15\right)^{4}-\left(T_{1}+273.15\right)^{4}\right)-\frac{k_{g} * l *\left(T_{1}-T_{2}\right)}{t_{g} / 4} \\
=p_{g} * c p_{g} * l * t_{g} / 8 * \frac{T_{1}-T_{1}^{i-1}}{\Delta t}
\end{gathered}
$$


b) Point 2 (similar for points 3, 4, 11, 12 and 13):

$$
\begin{gathered}
\dot{Q}_{\text {cond } 12}-\dot{Q}_{\text {cond } 23}=\dot{Q}_{\text {cap } 1} \\
\frac{k_{g} * l *\left(T_{1}-T_{2}\right)}{t_{g} / 4}-\frac{k_{g} * l *\left(T_{2}-T_{3}\right)}{t_{g} / 4}=p_{g} * c p_{g} * l * t_{g} / 4 * \frac{T_{2}-T_{2}^{i-1}}{\Delta t}
\end{gathered}
$$

c) Point 5 (similar for point 10):

$$
\begin{gathered}
\dot{Q}_{\text {cond } 45}-\dot{Q}_{\text {cond } 56}=\dot{Q}_{\text {cap } 5} \\
\frac{k_{g} * l *\left(T_{4}-T_{5}\right)}{t_{g} / 4}-\frac{\left(T_{5}-T_{6}\right)}{R_{\text {cond } 56}}=\frac{T_{5}-T_{5}^{i-1}}{R_{\text {cap } 5}} \\
R_{\text {cond } 56}=\frac{1}{\left(\frac{1}{R_{i 561}}\right)+\left(\frac{1}{R_{s 561}}\right)+\left(\frac{1}{R_{s 562}+R_{i 562}}\right)+\left(\frac{1}{R_{s 563}}\right)+\left(\frac{1}{R_{i 563}}\right)} \\
R_{\text {cap } 5}=R_{g 51}+\frac{1}{\left(\frac{1}{R_{i 51}}\right)+\left(\frac{1}{R_{s 51}}\right)+\left(\frac{1}{R_{i 52}}\right)}
\end{gathered}
$$

$\mathrm{R}$ for conduction R for capacity

$$
\begin{aligned}
R_{i 561} & =\frac{b_{l} / 2+t_{s} / 2}{k_{i} * t_{i}} \\
R_{s 561} & =\frac{b_{l} / 2+t_{s} / 2}{k_{s} * t_{s}} \\
R_{s 562} & =\frac{t_{s}}{k_{s} *\left(b_{f}-2 t_{s}\right)} \\
R_{i 562} & =\frac{\left(\frac{b_{l}-t_{s}}{2}\right)}{k_{i} *\left(b_{f}-2 t_{s}\right)} \\
R_{s 563} & =\frac{b_{l} / 2+t_{s} / 2}{k_{s} * t_{s}} \\
R_{i 563} & =\frac{b_{l} / 2+t_{s} / 2}{k_{i} * b_{i}}
\end{aligned}
$$$$
\begin{gathered}
R_{g 51}=\frac{\Delta t}{p_{g} * c p_{g} * l *\left(t_{g} / 8\right)} \\
R_{i 51}=\frac{\Delta t}{p_{i} * c p_{i} * t_{i} * t_{s}} \\
R_{s 51}=\frac{\Delta t}{p_{s} * c p_{s} * b_{f} * t_{s}} \\
R_{i 52}=\frac{\Delta t}{p_{i} * c p_{i} * b_{i} * t_{s}}
\end{gathered}
$$ 
d) Point 6 (similar for point 9):

$$
\begin{gathered}
\dot{Q}_{\text {cond } 56}-\dot{Q}_{\text {cond } 67}=\dot{Q}_{\text {cap } 6} \\
\frac{\left(T_{5}-T_{6}\right)}{R_{\text {cond } 56}}-\frac{\left(T_{6}-T_{7}\right)}{R_{\text {cond } 67}}=\frac{T_{6}-T_{6}^{i-1}}{R_{\text {cap } 6}} \\
R_{\text {cond } 67}=\frac{1}{\left(\frac{1}{R_{i 671}}\right)+\left(\frac{1}{R_{s 671}}\right)+\left(\frac{1}{R_{i 672}}\right)+\left(\frac{1}{R_{s 672}+R_{i 673}}\right)+\left(\frac{1}{R_{i 674}}\right)} \\
R_{\text {cap } 6}=\frac{1}{\left(\frac{1}{R_{i 61}}\right)+\left(\frac{1}{R_{s 61}}\right)+\left(\frac{1}{R_{i 62}}\right)+\left(\frac{1}{R_{s 62}}\right)+\left(\frac{1}{R_{i 63}}\right)}
\end{gathered}
$$

$$
\begin{gathered}
R_{i 671}=\frac{b_{w} / 4-t_{s} / 2}{k_{i} * t_{i}} \\
R_{s 671}=\frac{b_{w} / 4-t_{s} / 2}{k_{s} * t_{s}} \\
R_{i 672}=\frac{b_{w} / 4-t_{s} / 2}{k_{i} *\left(b_{f}-2 t_{s}\right)} \\
R_{s 672}=\frac{\left(\frac{b_{l}-t_{s}}{2}\right)}{k_{s} * t_{s}} \\
R_{i 673}=\frac{\left(\frac{b_{w}-2 b_{l}}{4}\right)}{k_{i} * t_{s}} \\
R_{i 674}=\frac{b_{w} / 4-t_{s} / 2}{k_{i} * b_{i}}
\end{gathered}
$$

$$
\begin{gathered}
R_{i 61}=\frac{\Delta t}{p_{i} * c p_{i} * t_{i} *\left(b_{l}-t_{s}\right)} \\
R_{s 61}=\frac{\Delta t}{p_{s} * c p_{s} * t_{s} *\left(b_{l}-t_{s}\right)} \\
R_{i 62}=\frac{\Delta t}{p_{i} * c p_{i} *\left(b_{f}-2 t_{s}\right) *\left(b_{l}-t_{s}\right)} \\
R_{s 62}=\frac{\Delta t}{p_{s} * c p_{s} * t_{s} *\left(b_{l}-t_{s}\right)} \\
R_{i 63}=\frac{\Delta t}{p_{i} * c p_{i} * b_{i} *\left(b_{l}-t_{s}\right)}
\end{gathered}
$$


e) Point 7 (similar for point 8):

$$
\begin{gathered}
\dot{Q}_{\text {cond } 67}-\dot{Q}_{\text {cond } 78}=\dot{Q}_{\text {cap } 7} \\
\frac{\left(T_{6}-T_{7}\right)}{R_{\text {cond } 67}}-\frac{\left(T_{7}-T_{8}\right)}{R_{\text {cond } 78}}=\frac{T_{7}-T_{7}^{i-1}}{R_{\text {cap } 7}} \\
R_{\text {cond } 78}=\frac{1}{\left(\frac{1}{R_{i 781}}\right)+\left(\frac{1}{R_{s 781}}\right)+\left(\frac{1}{R_{i 782}}\right)+\left(\frac{1}{R_{i 783}}\right)} \\
R_{\text {cap } 7}=\frac{1}{\left(\frac{1}{R_{i 71}}\right)+\left(\frac{1}{R_{s 71}}\right)+\left(\frac{1}{R_{i 72}}\right)+\left(\frac{1}{R_{i 63}}\right)}
\end{gathered}
$$

$$
\begin{aligned}
R_{i 781} & =\frac{\left(\frac{b_{w}-2 b_{l}}{2}\right)}{k_{i} * t_{i}} \\
R_{S 781} & =\frac{\left(\frac{b_{w}-2 b_{l}}{2}\right)}{k_{s} * t_{s}} \\
R_{i 782} & =\frac{\left(\frac{b_{w}-2 b_{l}}{2}\right)}{k_{i} *\left(b_{f}-t_{s}\right)} \\
R_{i 783} & =\frac{\left(\frac{b_{w}-2 b_{l}}{2}\right)}{k_{i} * b_{i}}
\end{aligned}
$$

$$
\begin{gathered}
R_{i 71}=\frac{\Delta t}{p_{i} * c p_{i} * t_{i} *\left(\frac{b_{w}-2 b_{l}}{2}\right)} \\
R_{s 71}=\frac{\Delta t}{p_{s} * c p_{s} * t_{s} *\left(\frac{b_{w}-2 b_{l}}{2}\right)} \\
R_{i 72}=\frac{\Delta t}{p_{i} * c p_{i} *\left(b_{f}-t_{s}\right) *\left(\frac{b_{w}-2 b_{l}}{2}\right)} \\
R_{i 73}=\frac{\Delta t}{p_{i} * c p_{i} * b_{i} *\left(\frac{b_{w}-2 b_{l}}{2}\right)}
\end{gathered}
$$

\section{f) Point14 (unexposed surface):}

$$
\dot{Q}_{c o n d 1314}-\dot{Q}_{r}=\dot{Q}_{c a p 14}
$$

$$
\begin{gathered}
\frac{k_{g} * l *\left(T_{13}-T_{14}\right)}{t_{g} / 4}+h_{c o n v c} * l *\left(T_{14}-T_{a c}\right)+\varepsilon_{c} * \sigma * l *\left(\left(T_{14}+273.15\right)^{4}-\left(T_{a c}+273.15\right)^{4}\right) \\
=p_{g} * c p_{g} * l * t_{g} / 8 * \frac{T_{14}-T_{14}^{i-1}}{\Delta t}
\end{gathered}
$$




\section{Notations:}

$\mathrm{W}_{\mathrm{e}}$ is the effective width;

$b_{\mathrm{w}}$ is the length of the web;

$b_{1}$ is the length of the lip;

$b_{\mathrm{f}}$ is the length of the flange;

$t_{s}$ is the thickness of the channel;

$t_{i}$ is $15 \%$ of the net width between steel studs and the edge $\left(t_{i}=0.15 T_{i}\right)$;

$b_{i}$ is $15 \%$ of the net width between steel studs and the edge on the other side of channel $\left(b_{i}=0.15 B_{i}\right)$;

$t_{g}$ is the thickness of the gypsum board on one side.

$\mathrm{h}_{\text {convh }}$ is convection heat transfer coefficient on the fire exposed side;

$\varepsilon_{\mathrm{h}}$ is emissivity on the fire exposed side;

$\mathrm{h}_{\text {convc }}$ is convection heat transfer coefficient on the cold side;

$\varepsilon_{\mathrm{c}}$ is emissivity on the cold side;

$\sigma$ is Stefan-Boltzmann constant;

$l$ is width of the panel $\left(b_{i}+b_{f}+t_{i}\right)$;

$\mathrm{p}_{\mathrm{g}}$ is density of gypsum board;

$\mathrm{cp}_{\mathrm{g}}$ is specific heat of gypsum board;

$\mathrm{k}_{\mathrm{g}}$ is thermal conductivity of gypsum board;

$\mathrm{p}_{\mathrm{i}}$ is density of insulation;

$\mathrm{cp}_{\mathrm{i}}$ is specific heat of insulation;

$\mathrm{k}_{\mathrm{i}}$ is thermal conductivity of insulation;

$\mathrm{p}_{\mathrm{s}}$ is density of steel;

$\mathrm{cp}_{\mathrm{s}}$ is specific heat of steel;

$\mathrm{k}_{\mathrm{s}}$ is thermal conductivity of steel;

$\mathrm{R}_{\text {condab }}$ is thermal resistance for heat transfer between point a and $\mathrm{b}$;

$\mathrm{R}_{\text {capa }}$ is thermal capacitance for point a;

$\dot{\mathrm{Q}}_{\mathrm{l}}$ is heat transfer rate on fire exposed side;

$\dot{\mathrm{Q}}_{\text {condab }}$ is heat conduction between point a and b;

$\dot{\mathrm{Q}}_{\text {capa }}$ is heat capacity for point a; 
$\dot{\mathrm{Q}}_{\mathrm{r}}$ is heat transfer rate on the cold side;

$\mathrm{T}_{\mathrm{ah}}$ is temperature of surrounding air on fire exposed side;

$\mathrm{T}_{\mathrm{ac}}$ is temperature of surrounding air on cold side;

$\mathrm{T}_{\mathrm{a}}$ is temperature of point $\mathrm{a}$;

$\Delta \mathrm{t}$ is time increment; 


\section{References}

[1] A. Shahbazian, Y.C. Wang, Calculating the global buckling resistance of thin-walled steel members with uniform and non-uniform elevated temperatures under axial compression, Thin-Walled Structures, 49 (2011) $1415-1428$.

[2] A. Shahbazian, Y.C. Wang, Application of the Direct Strength Method to local buckling resistance of thin-walled steel members with non-uniform elevated temperatures under axial compression, Thin-Walled Structures, 49 (2011) 1573-1583.

[3] A. Shahbazian, Y.C. Wang, Direct Strength Method for calculating distortional buckling capacity of cold-formed thin-walled steel columns with uniform and non-uniform elevated temperatures, Thin-Walled Structures, 53 (2012) 188-199.

[4] M. Feng, Y.C. Wang, J.M. Davies, Axial strength of cold-formed thin-walled steel channels under nonuniform temperatures in fire, Fire Safety Journal, 38 (2003) 679-707.

[5] Abaqus, v6.10 Documentation, Dassault Systèmes Simulia Corp., 2010.

[6] I. Rahmanian, Y.C. Wang, A combined experimental and numerical method for extracting temperaturedependent thermal conductivity of gypsum boards, Construction and Building Materials, 26 (2012) 707-722. [7] M. Feng, Y.C. Wang, J.M. Davies, Thermal performance of cold-formed thin-walled steel panel systems in fire, Fire Safety Journal, 38 (2003) 365-394.

[8] W. Benedikt, Heat transfer mechanisms and models for a gypsum board exposed to fire, International Journal of Heat and Mass Transfer, 55 (2012) 1661-1678.

[9] Committee of European Normalisation (CEN), Eurocode 1: Actions on structures - Part 1-2: General actions - Actions on structures exposed to fire, European Standard, Brussels, 2002.

[10] Committee of European Normalisation (CEN), Eurocode 3: Design of Steel Structures - Part 1-2: General Rules - Structural Fire Design, European Standard, Brussels, 2005.

[11] B. Salhab, Y.C. Wang, A Study of The Thermal Performance of Cold-Formed Thin-Walled Perforated Steel Studs (Thermal Studs) in Fire, in: B.M. Ramesh, M. Arup (Eds.), ASCE, 2004, pp. 95.

[12] Y.C. Wang, Steel and composite structures: behaviour and design for fire safety, Spon, London, 2002. [13] Y.C. Wang, I. Burgess, F. Wald, M. Gillie, Performance-Based Fire Engineering of Structures, CRC Press, London, 2012.

[14] R.M. Lawson, Building design using cold formed steel sections: fire protection, Steel Construction Institute, 1993.

[15] B.W. Schafer, Local, Distortional, and Euler Buckling of Thin-Walled Columns, Journal of Structural Engineering, 128 (2002) 289-299. 